\title{
Validation and Improvement of the European Customer Satisfaction Index for the Spanish Wine Sector
}

\begin{tabular}{|r|l|}
\hline Journal: & The TQM Journal \\
\hline Manuscript ID & TQM-07-2016-0056.R4 \\
\hline Manuscript Type: & Research Paper \\
\hline Keywords: & $\begin{array}{l}\text { Customer Satisfaction, Quality Management, Organizational structure, } \\
\text { Value analysis, Corporate Image, Customer Loyalty }\end{array}$ \\
\hline \multicolumn{2}{|l}{} \\
\hline
\end{tabular}




\section{Validation and Improvement of the European Customer Satisfaction Index for the Spanish Wine Sector}

Purpose: A study of the Spanish wine sector, in this case specifically the Designation of Origin (DO) Somontano, requires validation of the European Customer Satisfaction Index (ECSI), which also needs to be improved and adapted to obtain more information on customer satisfaction.

Design/methodology/approach: Applying the ECSI model, based on structural equation modeling (SEM) using partial least squares (PLS).

Findings: An empirical analysis shows that the importance of customers' expectations and perceived quality are the most influential factors in achieving satisfaction. Also highlighted in the new model is the linkage between service and product qualities in a unique variable, total quality.

Originality/value: In addition to validating the ECSI model for DO Somontano, a new innovative implementation was developed and tested to improve the calculation of satisfaction.

Keywords: Customer satisfaction, quality management, organizational structure, value analysis, corporate image, customer loyalty 


\section{Introduction}

In order to obtain greater benefits all the wine companies desire to know how can they quantify the customer satisfaction with the purpose of acquiring a strategic advantage with their competitors. One of the most effective way to carry it out is through an econometric study.

Therefore, enterprises design different measurement tools that allow them to comprehend the customer satisfaction indexes. An evaluation and analysis of these satisfaction indexes constitute an indispensable mechanism to measure the customer's needs.

Over the years, many authors have studied customer satisfaction and what it represents. One of the most important author was Oliver (1980). He explained the satisfaction as a feeling that comes from one or several experiences and he is also in agreement with Woodruff and Gardial (1991). A different theory was proposed by Fornell, Anderson, Lehmann and Johnson (1995), the satisfaction represents the overall evaluation of the accumulative experience that customers obtain while they are using or trying the product and/or service over time. Croning and Taylor (1994) and Jones and Suh (2000) suggested that satisfaction is an accumulative evaluation and, consequently, represents an overall judgment rather than a specific transaction review.

Therefore, based on this double perspective (specific transaction and accumulative vision), the analysis of satisfaction stands out for its business impact and it can be introduced in the wine sector.

An analysis from an accumulative point of view allows us to understand satisfaction as an important indicator in the global market (macroeconomic view) and in each company (microeconomic view), since profits and product and/or service results are evaluated from customers' use over a long period of time (Anderson and Fornell, 1994; Oliver, 1997).

Customer satisfaction analysis has attained more importance since the 1980s due to an increase in competition and service sector development. Consequently, several countries have designed and implemented national indexes to measure customer satisfaction. These indexes, besides obtaining the level of clients satisfaction, also allow to interpret which are the indicators that are involved in the acquisition of the satisfaction that are able to anticipate the future clients' demands and also to evaluate the effectiveness of the strategies applied. The most famous and pragmatic indexes are the American Customer Satisfaction Index (ACSI) and the Swedish Customer Satisfaction Barometer (SCSB) developed by Fornell, the Deutsche Kundenbarometer (DK) created by Eklöf, the Norwegian Customer Satisfaction Barometer (NCSB) established in 1998 by Andreassen and Lindestad and the European Customer Satisfaction Index (ECSI) studied by Eklöf in 2000 which is used in our study. These indexes are proposed to value customer satisfaction under the accumulative satisfaction view with the purpose of measuring customer satisfaction ranks through variables formed when a product or service is utilized (Fornell et al., 1996).

When a product is marketed, companies should know which guidelines must be followed to obtain a better customer satisfaction. One of the most precise method for estimating customer satisfaction is the ECSI model, based on a structural model (SEM) and validated through a partial least squares (PLS) statistical method, the SmartPLS3. In 
this research, another new model, which accepts every improvement, has been designed to deliver more accuracy.

\section{Theoretical Approach}

\section{Literature Review}

There are not many articles related with the wine customer satisfaction.

In the research carried out by Costanza Bianchi "Precedents of consumer brand loyalty in the Australian wine industry" (2014) and "Consumer Brand Loyalty in the Chilean Wine Industry (2015)", loyalty has been explained through an econometric model. She proposed a conceptual SEM model of consumer brand loyalty with five different latent variables: Wine knowledge, wine experience, wine brand satisfaction, wine brand trust and wine brand loyalty. Our study will focus on getting satisfaction because loyalty is its consequence.

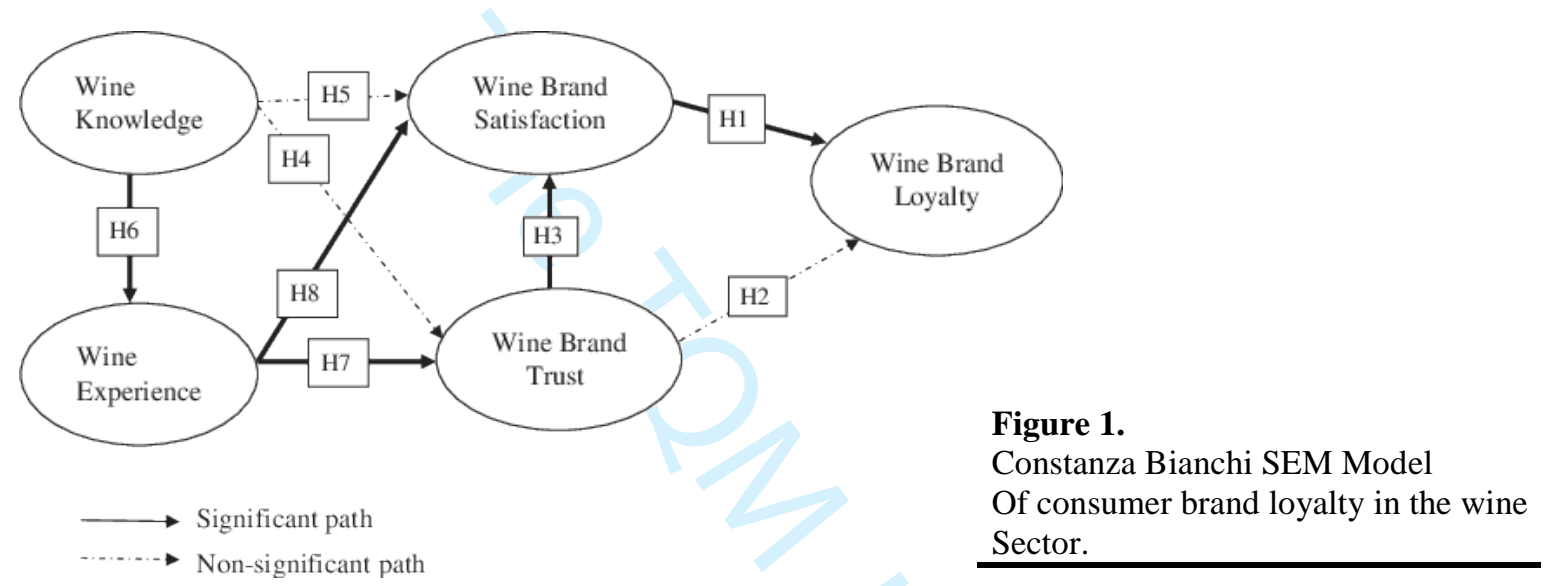

The main difference between our studies is the lack of expectations and satisfaction that the brand generates in the consumers through its image, in other words, it needs greater implication of the Denomination of Origin to attract new consumers through its wine prices and quality with an appropriate Marketing strategy.

Other related article is the Jingxue Yuan research (2018): "A model of wine tourist behaviour: a festival approach", which determined a temporal model of wine tourists behaviour according to the consumer attitudes and related concepts with regard to past behaviour, satisfaction, perceived value and behavioural intentions.

Most ECSI model researches have been used to establish customer satisfaction based on SEM and estimated through PLS. For example, four studies have been conducted in this area of knowledge: 'The application of European Customer Satisfaction Index (ECSI) model in determining the antecedents of satisfaction, trust and repurchase intention in five-star hotels in Shiraz, Iran' written by Mojtaba Kaveh, Seyed Alireza Mosavi and Mahnoosh Ghaedi (2012); 'ECSI - Customer Satisfaction Modelling and Analysis: A Case Study' by Enrico Ciavolino and Jens J. Dahlgaard (2007); 'An integrated framework based on the ECSI approach to link mould customers' satisfaction and product design' by Irene Ferreira, José Cabral and Pedro Saraiva (2010); and 'An application of European Customer Satisfaction Index (ECSI) in business to business (B2B) context' by Mohammad Hossein Askariazad and Nazila Babakhani (2015). 
The shortage of articles that analyze customer satisfaction from the structural model of the variables belonging to the ECSI model has allowed us to obtain innovations about the importance of satisfaction in a collective brand such as Designation of Origin (DO) wines. Furthermore, this research has presented a new ECSI model for obtaining DO customer satisfaction with better results.

\section{Proposed Methodology}

DO Somontano wines belong to a collective mark, which is why an ECSI model can be performed to analyze customer satisfaction of a wine group produced in the same region and not only for a specific Somontano wine brand. Therefore, in this article, the ECSI model is utilized to evaluate customer satisfaction of DO (Designation of Origin) Somontano wines, optimizing its predictive capacity. The variance analysis is developed for the PLS algorithm (Chin, 1998), using smartPLS as a study tool.

\section{European Customer Satisfaction Index}

Several countries have developed National Satisfaction Indexes, based on structural equation models (SEM), which help to achieve the causal analysis of the different variables involved in the structural models and determine the amount of client satisfaction, this variables influence on satisfaction so they are a consequence of customer satisfaction or dissatisfaction from the consumption of a product and service. "The success of the application of the Swedish and American indexes to evaluate customer satisfaction, which included the European Organization for Quality (EOQ), the European Foundation for the Quality Management (EFQM) and a group of European academic experts who formed the ECSI technical committee, in charge of setting the theoretical basis of the model and developing its methodology and requirements "(Eklöf, 2000).

The European customer satisfaction index represents another alternative of the ACSI model (Eklöf, 2000). "Customer expectations, perceived quality, perceived value, customer satisfaction, and customer loyalty structures are the same as in the ACSI model. As well as indicators for evaluating variables and their causal relationships, except in indicators designed to evaluate loyalty. The European model assesses the probability of retention, the possibility of recommending the company or brand and the likelihood of increased consumption of the product and / or service. "

The seven ECSI variables intervening in the estimated model are latent variables that can only be measured indirectly with their indicators or manifested variables. The design used for evaluating the model was determined by the ECSI technical committee, based on Swedish and American indicators, by developing a multi-item questionnaire for collecting customer information (Coelho and Esteves, 2007). The utilization of questions or multiple items for reviewing these variables increases the estimated model precision. Moreover, in the questionnaire design, generic questions or items are used to allow a higher degree of flexibility when this structural model is applied in a different product or service sector (Tenenhaus, 2008). As seen before, satisfaction is the latent variable to be studied and it is related to the model's other six latent variables or qualities which belongs to the product or service. These qualities are formed by value, image, expectations, loyalty and quality, which is divided into perceived quality of product and the perceived quality of service. 


\section{Perceived Quality}

Perceived quality is the extent of the discrepancy between customer expectations or wishes (expected service) and their perceptions (perceived service). Furthermore, quality is whatever customers say it is, in other words, product or service quality arises from every single customer perception after each product or service use. Likewise, we must realize that quality consist on a long-range overall evaluation of the products or services provided to customers (Anderson and Fornell, 1994). In the study of perceived quality, this variable is sometimes divided into two different variables to evaluate other perspectives; the technical or result view and the functional or process perspective. Analyzed quality from a result perspective is called Quality 1, hardware-perceived quality or product-perceived quality. Meanwhile, if it is evaluated from a functional perspective, it is called Quality 2, humanware-perceived quality or service-perceived quality. This distinction between service quality and product quality is a distinguished feature of the ECSI model (Eklöf et al., 2000) and (Kristensen et al., 1999). This shows that product- and service-perceived qualities have a direct and positive causal relationship in customer satisfaction related to ECSI application.

Value

Zeithaml (1988) defined the concept of perceived value as an overall evaluation of how customers categorize a product based on their perceptions. In other words, according to Lam (2004), it could be considered as customer benefits received from total costs. The price must be included in all assembly expenses (Andreassen and Lindestad, 1998), as must other psychological or derivative costs from the customer effort (Oliver, 1997). Furthermore, Anderson, Fornell and Lehmann (1994) pointed out that perceived value is linked to product- and/or service-perceived quality and the price spent on it. Therefore, value is also defined as the quality-price relationship. When an increment is expected in both variables, it leads to an increase in each customer's satisfaction. It also provides important information on customer perception of the product and/or service, because price is a significant component of perceived value and it is considered one of the most important drivers of satisfaction.

\section{Image}

In reference to Andreassen and Lindestad (1998), image is the reputation of the company, product and/or service offered to the customer. It is formed and established in the customer's mind through communication with potential customers and the experience they acquire of product and/or service use whenever they are satisfied with the product and/or service. As this image improves, so does the excellence of the organization. Similarly, image has a direct, causal and positive relationship with customer satisfaction, focusing directly on customer loyalty. Martensen (2000) realized that image influences positively on customer expectations and product and/or service values traded by the company. In this study, corporate image is a previous variable of satisfaction and it also has a causal relationship with other model variables, such as expectations and loyalty.

\section{Expectations}

Customers create expectations of the product or service in a previous shopping stage and the consumer experience then comparatively judges the result and its initial expectations to analyze if there is a positive or negative disagreement. Oliver (1980) posited that if the resultant perception exceeds expectations and is positive, the customer will be satisfied with the product or service. Therefore, expectations will have 
a causal and direct relationship over this perceived product or service, and over the product and/or service value, positively influencing the satisfaction of customer perception.

\section{Loyalty}

Oliver (1997) defined loyalty as deep customer commitment to repurchase the same product, brand or service consistently in future, in spite of situational and marketing influences that may have enough potential to produce a behavioral change in the customer.

Loyalty is the final variable representing the efficiency of a model. If customer loyalty rises, future profits are assured, supporting the quality levels of the company's product and/or service. Moreover, word-of-mouth communication by satisfied customers loyal to the company improves its global prestige, reducing necessary investment in attracting new customers (Anderson and Fornell, 2000).

Customer loyalty can be measured through repeat purchase intention and customer sensitivity to price variations in the future. Image and satisfaction are variables with a direct and positive causal relationship with customer loyalty. Finally, loyalty stands out as the consequence of model satisfaction, evaluated from two different perspectives. The first is based on customer repeat purchase evaluation, and the second on how price variation can change a decision to purchase another product and/or service.

\section{SEM - Structural Equation Modelling}

SEM is a powerful technique that enables researchers the capability of measuring direct and indirect effects that cannot be analyzed because they are hypothetical or not directly observable. Referring to the definition of its creator, Sewall Wright (1921), the model is a statistical method in order to estimate strong relationships by using casual assumptions and statistical data. The fundamental characteristic of SEM is the possibility to allow multiple regressions between variables and latent variables and It is referred to these models as a second generation of multivariate analysis (Fornell, 1982).

- $\quad$ PLS-SEM (Variance-based approach). It is a causal modelling approach which maximize the explained variance of the dependent latent constructs (Hair, 2015).

o Small groups of data

0 Measurements that not been fully developed

0 Theories that not been absolutely developed

o Data with non-normal distribution

0 The presence of formative and reflective indicators

0 Interest in predicting the dependent variable

ECSI Method: ECSI model formulation applied to the wine sector The ECSI method is designed by structural equation modeling (hereinafter SEM) using partial least squares (hereinafter PLS, Eklöf, 2000 and Henseler, Ringle and Sinkovics, 2009) as an estimation medium. Designed to explain causes and effects on customer satisfaction, the structural model also assesses causal relationships between various latent variables prior to satisfaction, corporate image, customer expectations, perceived quality and perceived value. In addition, it can evaluate the existing direct causal relationship between satisfaction and loyalty. The European model contains retention probability, the possibility of recommending the company or trademark and the probability of increasing product and/or service use. This model does not include associated incidences, provided by customers in disagreement with the "complain" variable. If we focus on figure 1, the exogenous latent variables are independent of the 
other variables and they do not receive impacts on the graphic representation as only arrows emerge. The image in the ECSI model is the only variable of this type. By contrast, the other variables in the model are endogenous and dependent on at least one equation of the model. In the graphic representation of the model, endogenous variables are those that receive arrows.

Building on the theoretical development of ECSI latent variables, linked to the conclusions obtained in the evaluated process of the wine sector and the workgroup consisting of DO Somontano experts and researchers from the University of Zaragoza. The following thirteen hypotheses were proposed.

H1: Image positively affects wine customer expectations.

H2: Image positively affects wine customer satisfaction.

H3: Image positively affects wine repurchase.

H4: Customer expectations positively impact on model satisfaction.

$\mathrm{H} 5$ : Customer expectations positively influence expected benefits from wine intake compared with its price.

H6: Expectations created by customers increase the perception of product-perceived quality (result perspective).

H7: Expectations created by customers increase the perception of service-perceived quality (functional perception).

H8: Perceived product quality will have a positive effect on the customer's perceived value.

H9: Perceived customer product quality positively influences customer satisfaction.

H10: Perceived service quality will have a positive effect on customer-perceived value.

H11: Perceived customer-service quality positively influences customer satisfaction.

H12: Perceived value directly influences customer satisfaction.

H13: Loyalty is a consequence of customer satisfaction.

Figure 2.

ECSI Path diagrams,

Hypothesis.

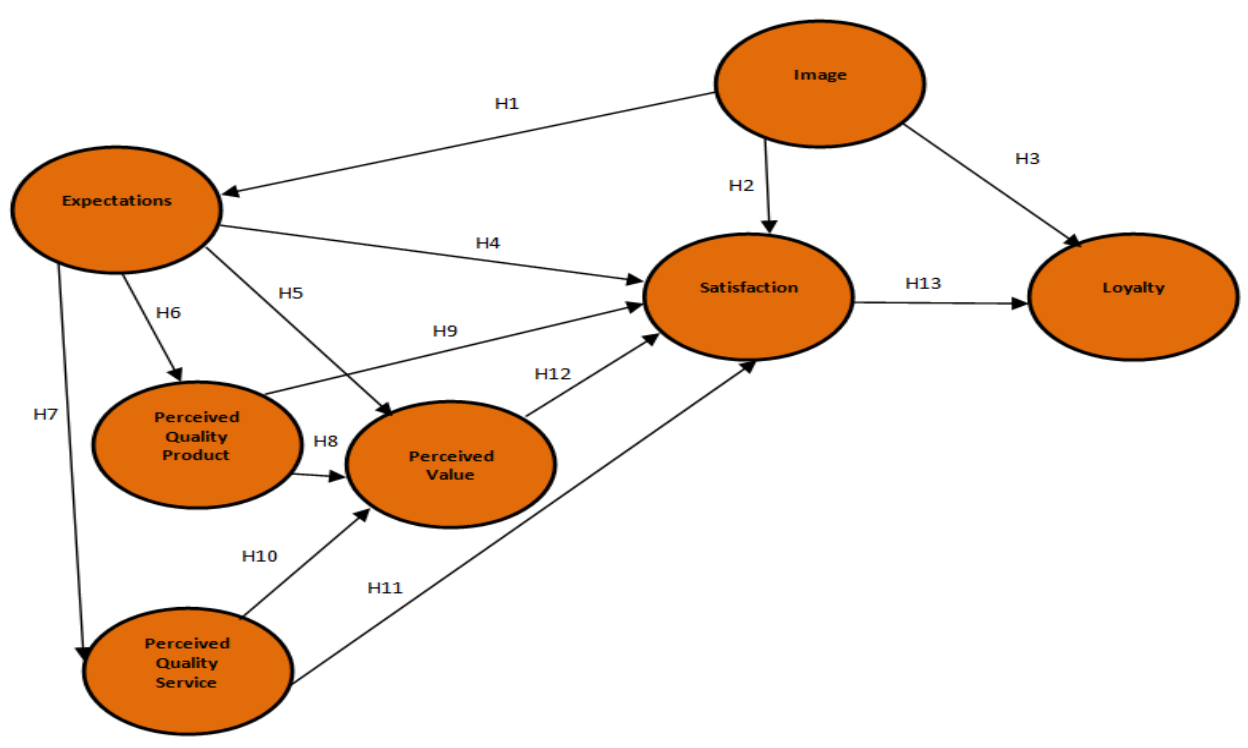

A structural questivinlane wiur ciuseu dissweis was uesıgneu vy usmly estavismeu standards created by the ECSI committee to associate manifest variables with other latent variables, taking into consideration the recommendations and proposals designed by DO Somontano experts and researchers from the University of Zaragoza. Regarding sample size in the proposed ECSI model, Barclay, Higgins and Thompson (1995) indicated that the latent satisfaction variable is the only one with a higher number of structural paths (six). Therefore, in a PLS estimation, the questionnaire should be 
adequate, in a good way, with a sample of 60 cases $(6 \times 10)$. Cohen says that the G*Power software developed by the University of Kiel in Germany has to be used to delete a null hypothesis when it is false in the potency calculation. Conventionally, an $\alpha$ $=0.05$ and a $\beta=0.20$ are assumed to achieve a proper balance between these types of errors. Concluding on statistics terms, potency is equal to $1-\beta$, so the suitable power level should always be equal or higher to 0.8 (Cohen, 1998).

A sampling with a non-probabilistic method was used, specifically, sampling selection, to extract the population. It was performed through the snowball sampling method. This type of sampling consists of selecting respondents using reference systems through the other respondents. In our study, the questionnaire was distributed to a list of students, professors and university staff of the University of Zaragoza and DO Somontano customers. A link was also published in a Somontano communication group. This type of sample allowed us to know the exact scope of our survey.

The chosen cut point was decided by acquiring sufficient samples that could represent the effect of the sample as medium. Therefore, at least 98 responses must be obtained to achieve sufficient numbers of samples to reach $80 \%$ potency. This number of samples complies with the recommended criterion and proposed modeling in previous research (at least 60 cases). Initially, owing to the temporary limitation of the research, a minimum number of 150 cases was set as a target, which also satisfies the criterion established above. Data collection concluded after 60 days. A total of 244 cases was obtained, of which 170 belonged to wine customers in the DO quality region. The other 74 were not wine drinkers or only drank wine with no designation of origin.

The calculated process of the Cohen power is represented next, but in this case, using the sample size obtained in the data collection as a basis. A 99.9\% potency was obtained from these 244 answers in this sample type. Therefore, the size of the sample sufficed to reach the objectives of the present study.

Figure 3.

$\alpha$ and $\beta$ Error for the potency estimation with 6 regressors and 244 inquests

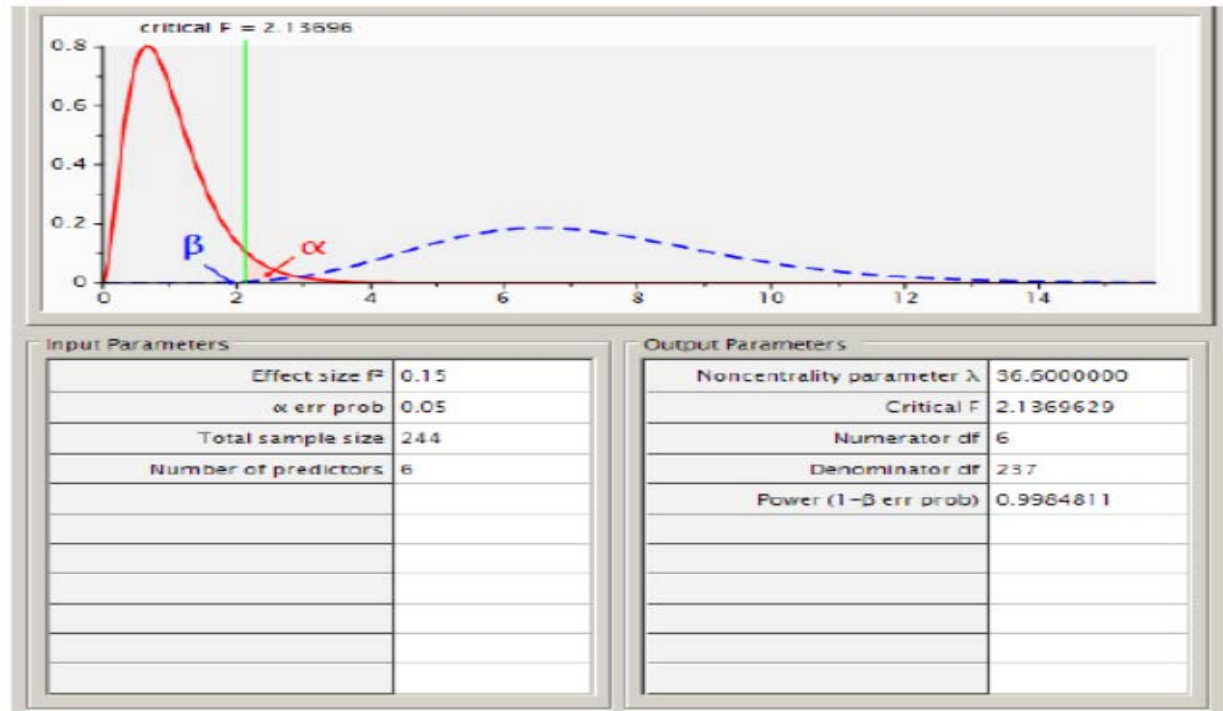

Analysis of the proposed structural model and the hypothesis contrast. Original ECSI model results:

The purpose of this research is to study and verify the factors with the most influence on wine DO customer satisfaction. SEM divided into two parts was used to qualify satisfaction. Firstly, the measure model showing the amount of linkage of the latent 
variables with their indicators. And secondly, the structural model, which highlights the relationship between the other latent variables. It is validated according to a PLS statistical method, the SmartPLS3. The reliability of the measurement model instrument can be observed in the following tables.

\begin{tabular}{llllr}
\hline $\begin{array}{l}\text { Latent } \\
\text { Variables }\end{array}$ & $\begin{array}{l}\text { Composed } \\
\text { Reliability }\end{array}$ & $\begin{array}{l}\text { Cronbach's } \\
\text { Alpha }\end{array}$ & AVE & \\
\hline Product Quality & 0.847 & 0.764 & 0.582 & \\
Service Quality & 0.872 & 0.804 & 0.631 & Table I. \\
Expectations & 0.915 & 0.861 & 0.782 & Internal Consistency \\
Image & 0.877 & 0.817 & 0.642 & Evaluation and Average \\
Loyalty & 0.852 & 0.769 & 0.59 & Variance Extracted, AVE \\
Satisfaction & 0.884 & 0.826 & 0.658 & \\
Value & 0.838 & 0.714 & 0.634 &
\end{tabular}

Based on the above table, internal consistency is explained by composed reliability and Cronbach's alpha, where it is indicated that all the latent variables fulfill the established criterion, and, therefore, it is deduced that the measurement scales are extremely reliable, with a composed reliability close to 0.9 .

The average variance extracted (AVE) calculation is recommended to be over 0.50 , with this case establishing over $50 \%$ of the construct variance defined by its indicators. The following table details the AVE square root values of the latent variables in its matrix diagonal. Below the diagonal, the existing correlations between the latent variables are shown to obtain the discriminant validity using the Fornell-Larcker criterion.

\begin{tabular}{|c|c|c|c|c|c|c|c|c|}
\hline $\begin{array}{l}32 \\
3 \\
3\end{array}$ & Product Quality & Service Quality & Expectations & Image & Loyalty & Satisfaction & Value & \\
\hline 34Product Quality & 0.763 & & & & & & & \\
\hline 35Service Quality & 0.457 & 0.794 & & & & & & \\
\hline 36 Expectations & 0.619 & 0.402 & 0.884 & & & & & Table II. \\
\hline $\begin{array}{l}\text { 37 Image } \\
38\end{array}$ & 0.34 & 0.427 & 0.433 & 0.801 & & & & Discriminant \\
\hline 35-oyalty & 0.507 & 0.387 & 0.555 & 0.427 & 0.768 & & & validity evaluation, \\
\hline 4@Satisfaction & 0.705 & 0.51 & 0.761 & 0.4 & 0.668 & 0.811 & & Fornell-Larcker \\
\hline $4 \pi$ Value & 0.416 & 0.371 & 0.508 & 0.221 & 0.288 & 0.542 & 0.796 & criterion. \\
\hline
\end{tabular}

According to table II, the value correlations between the constructs are smaller than the average variance shared between a construct and its indicators, so it can be confirmed that every latent variable complies with the established criterion. Before evaluating the structural modeling, the multicolinearity of the explicative variables must be examined. This means they must be independent from each other.

After demonstrating the reliability of the model, structural modeling is implemented. This assesses the importance and magnitude of the relationships between the latent variables. Therefore, the quantity of variance explained by each endogenous variable $\left(\mathrm{R}^{2}\right)$, path coefficients $(\beta)$ and the Stone-Geisser $\left(Q^{2}\right)$ test are determined in the following tables.

Chin (1998) classifies the values of the endogenous variables $\mathrm{R}^{2}$ in the PLS estimated models as substantial if values are over 0.67 , moderated if they are over 0.33 and discrete or poor if values are under 0.19. 


\begin{tabular}{llll}
\hline Latent Variables & $\mathbf{R}^{2}$ & Communality & \\
\cline { 1 - 2 } Product Quality & 0.384 & 0.582 \\
Service Quality & 0.162 & 0.631 & \\
Expectations & 0.188 & 0.782 & \\
Image & & 0.642 & \\
Loyalty & 0.477 & 0.59 & \\
Satisfaction & 0.701 & 0.658 & Table III. \\
Value & 0.298 & 0.634 & $\mathrm{R}^{2}$ Endogenous \\
GoF & 0.49 & & Latent Variables \\
\hline
\end{tabular}

In accordance with the obtained data, the explained variance of the endogenous variables $\mathrm{R}^{2}$ only reaches qualified values as substantial ones in the satisfaction variable; moderate values for the product quality and loyalty variables and the variances for the other variables are classified as discrete. Likewise, $70 \%$ of the satisfaction variance is acquired by the four previous constructs and $47.8 \%$ of the loyalty variance can be interpreted by the satisfaction and image constructs. Likewise, communality values over 0.5 indicate that the model has predictive validity.

According to Falk and Miller, the explained variance of all the endogenous variables $\left(\mathrm{R}^{2}\right)$ results over 0.1 . Therefore, it can be considered that the formulated relationships among latent variables have an acceptable predictive level.

Chin states that if the influence of a particular latent variable over a dependent construct has a significant impact, the size effect $\mathrm{f}^{2}$ must be evaluated. The resulting criteria may establish that the predictor could exhibit a low (0.02), medium (0.15) or high (0.35) effect in the structural model (Cohen, 1988).

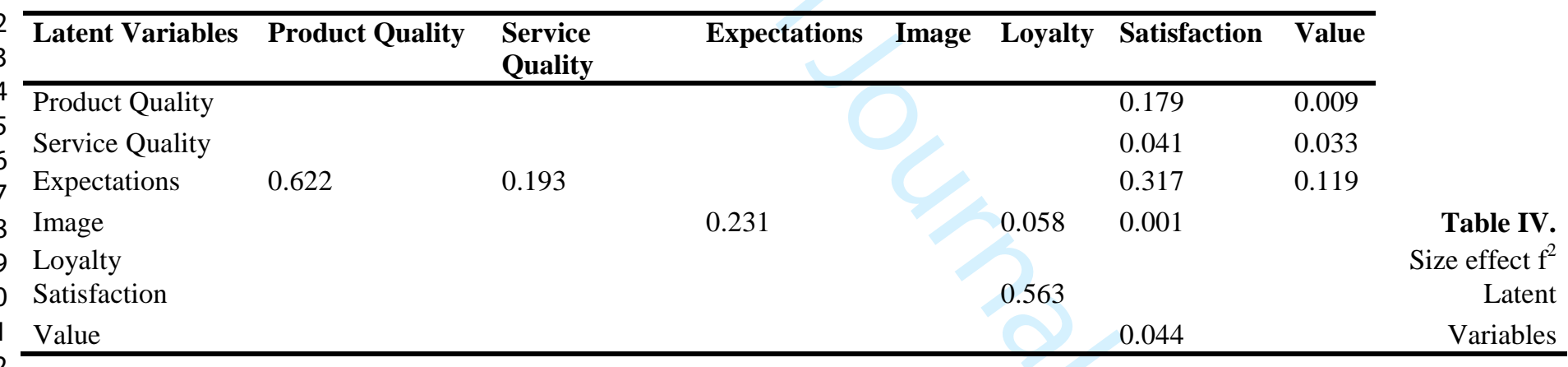

Statistical significance must be verified applying the resampling method, bootstrapping and checking the t-student value before considering the size of the path coefficients. The t-student statistic values over 0.99 are useful for a one-tail test. Besides, it is ratified that if a p-value is lower than the level of $\alpha$ signification, established as $\alpha=0.05$, a null hypothesis is not rejected when it is true. 
3

4

5

6

7

8

9

\begin{tabular}{|c|c|c|c|c|c|c|c|}
\hline Latent Variable & $\begin{array}{l}\text { T- } \\
\text { Student }\end{array}$ & p-value & $\begin{array}{l}\text { Path } \\
\text { Coefficient }(\beta)\end{array}$ & $\begin{array}{l}\text { Variables } \\
\text { Correlation }\end{array}$ & $\bar{B} * \mathrm{CV}$ & $\begin{array}{l}\text { Variance B } \\
\text { explained by A }\end{array}$ & \\
\hline Product Quality -> Satisfaction & 6.776 & 0 & 0.309 & 0.705 & 0.21785 & $21.78 \%$ & \\
\hline Product Quality -> Value & 1.529 & 0.127 & 0.106 & 0.416 & 0.0441 & $4.41 \%$ & \\
\hline Service Quality -> Satisfaction & 2.647 & 0.008 & 0.134 & 0.51 & 0.06834 & $6.83 \%$ & \\
\hline Service Quality -> Value & 2.376 & 0.018 & 0.173 & 0.371 & 0.06418 & $6.42 \%$ & Table V. \\
\hline Expectations ->Product Quality & 11.833 & 0 & 0.619 & 0.619 & 0.38316 & $38.32 \%$ & T-Student, \\
\hline Expectations ->Service quality & 6.716 & 0 & 0.402 & 0.402 & 0.1616 & $16.16 \%$ & p-value and \\
\hline Expectations -> Satisfaction & 7.302 & 0 & 0.437 & 0.761 & 0.33256 & $33.26 \%$ & path \\
\hline Expectations -> Value & 4.262 & 0 & 0.373 & 0.508 & 0.18948 & $18.95 \%$ & coefficients, \\
\hline Image -> Expectations & 7.471 & 0 & 0.433 & 0.433 & 0.18749 & $18.75 \%$ & \% variance $\mathrm{B}$ \\
\hline Image -> Loyalty & 3.385 & 0.001 & 0.19 & 0.427 & 0.08113 & $8.11 \%$ & explained \\
\hline Image -> Satisfaction & 0.62 & 0.536 & 0.018 & 0.4 & 0.0072 & $0.72 \%$ & by the \\
\hline Satisfaction -> Loyalty & 11.007 & 0 & 0.592 & 0.668 & 0.39546 & $39.55 \%$ & latent \\
\hline Value -> Satisfaction & 2.777 & 0.006 & 0.138 & 0.542 & 0.0748 & $7.48 \%$ & variables \\
\hline
\end{tabular}

Referring to table $\mathrm{V}$, all the t-student distribution values correspond to the relationships of each variable, which are statistically significant, excluding the values corresponding to the relationship between the image and satisfaction variables, with a t-student value of 0.620 , which is under the 1.98 established value and with a p-value over 0.05 . This is also seen between product quality and value variables with a 1.529 t-student value, under the established 1.98 and with a p-value over 0.05 .

This table also captures the contribution of each endogenous variable that is obtained from the multiplication of the path and correlation coefficient among each variable and the other endogenous variables, which represents the relative magnitude of the statistical relationships proposed in the model.

The impact generated by expectations over product quality is highlighted as the most important relationship in this model with a 0.619 value, followed by the relationship between satisfaction and loyalty with a 0.592 value, as well as the relationships between expectations and satisfaction, expectations and service quality and image and expectations, with this coefficient respectively, 0.437, 0.402, and 0.433. Likewise, it is important to note the low impact of the variable image on loyalty with a 0.190 value, especially the null impact that the image variable has on satisfaction with 0.018. Therefore, if the values proposed by Chin (1998) are considered, which indicate that the standard path coefficients must reach at least a 0.2 value, and ideally be over 0.3 , to be significant, six of the 13 relationships between the model variables are not significant.

However, according to the proposition put forward by Falk and Miller (1992), who determined a reasonable contribution of the explained variance in an endogenous construct from other latent variables, obtained by multiplying the path coefficient $(\beta)$ and the correspondent correlation coefficient between both variables, an empirical rule softer than Chin's (1998) proposition was implemented, determining that a predictive variable should explain at least $1.5 \%$ of the variance of two variables.

Therefore, in reference to Falk and Miller, who showed that a predictive variable should explain at least $1.5 \%$ of the variance of a predicted variable, all the relationships of this model exceed the established threshold except the relationship between image and satisfaction, which represents a $0.72 \%$ value.

Another parameter considered for evaluation in the structural model is Stone-Geisser's $\mathrm{Q}^{2}$. This criterion is used to analyze the predictive capacity of the model's latent 
variables, utilizing the blindfolding procedure. The redundancy of the acquired crossvalidation must be analyzed. It is obtained when the prediction is performed by the constructs foretelling the analyzed endogenous variable. If the cross-validation (CV) value acquired in the procedure and according to an endogenous latent variable is larger than zero (especially in cross-validation redundancy instead of CV communality), their explicative variables are considered to provide predictive relevance. The CV calculated for each variable is as follows: product quality (0.209), service quality (0.091), expectations $(0.141)$, loyalty $(0,272)$, satisfaction $(0.445)$, and value $(0.162)$. Every variable is considered to supply predictive relevance.

Finally, goodness of fit (GoF) is detailed (Chin, based on Tenenhaus's work in the variance approach) in table III, where the efficiency of the measuring model and the structural model are evaluated. Although the quality thresholds are not defined, the value of $0.10,0.25$ and 0.36 corresponds to low, medium and high predictions. The GoF value in our model is 0.49 , so the model has a good adjustment, with a high overall efficiency and the defined variables can explain the model correctly.

\section{Model ECSI Discussion:}

As mentioned above, starting from this recent research on data that can analyze the latent satisfaction variable, it has been observed that its variance can be highly explained from its antecedents. Since the value of R2 is 0.701 , we can explain/determine $70 \%$ of its variance. Moreover, the variable with more influence in the DO wine customer satisfaction is the expectation generated by them.

From $33.26 \%$ of the satisfaction variance explained by expectations $(\beta=0.437$; correlation $=0.761)$ and its medium predictor effect on satisfaction $\left(\mathrm{f}^{2}=0.317\right)$, it can be inferred that these parameters bear out the direct and positive influence of expectations on customer satisfaction and thus confirm hypothesis $\mathrm{H} 4$ (customer expectations positively impact on model satisfaction).

Another variable that also influences the perception of customer satisfaction is perceived product quality. Since $21.78 \%$ of satisfaction variance is interpreted by perceived product quality $(\beta=0, .619$; correlation $=0.619)$, with a high predictor effect on satisfaction $\left(f^{2}=0.622\right)$, hypothesis H9 (perceived customer product quality positively influences customer satisfaction) is supported. Therefore, customers who can perceive a high level of wine quality after drinking it, will reach high levels of satisfaction and will increase their expectations in future transactions.

Other variables that influence customer satisfaction, such as perceived value and perceived service quality, contribute in a lesser way to achieving customer satisfaction, although obtained results confirm hypothesis H11 (perceived customer-service quality positively influences customer satisfaction), and H12 hypothesis (perceived value directly influences customer satisfaction). Therefore, a customer will be satisfied when the perceived value of the wine intake is higher than its supposed cost. The value can be evaluated as perceived quality/price or benefits/cost ratio.

Finally, the relationship between image and satisfaction was analyzed, with the result that satisfaction variance explained by image is practically null. $(\beta=0.018$; correlation= 0.4 ) and its predictor effect is also null $\left(\mathrm{f}^{2}=0.001\right)$. Consequently, the data do not allow us to appreciate a causal relationship between the variables and hypothesis $\mathrm{H} 2$ (image positively affects wine customer satisfaction). This hypothesis must be discarded. According to perceived value, its variance is moderately explained by its antecedents, achieving a $0.298 \mathrm{R}^{2}$ value, so its antecedents permit it to explain almost $30 \%$ of its variance. 
It is important to highlight the power of expectations as one of the variables that most influences perceived value; $18.95 \%$ of the perceived value variance is explained by expectations $(\beta=0.373$; correlation $=0.508)$ and its predictor effect on the value is medium $\left(\mathrm{f}^{2}=0.119\right)$ confirming hypothesis H5 (customer expectations positively influence expected benefits from wine intake compared with its price. Therefore, wine use accomplishes a series of benefits, such as social prestige, feeling calm and enjoying leisure time. It also meets some social needs. Consequently, customers are prepared to pay for a series of wine properties, such as product quality assurance, food security, information and education offered to customers, product image and design.

Perceived service quality and perceived product quality intervene moderately on customer perceived value formation. The obtained results are important to evaluate the relationship between product quality and perceived value, although the $4.41 \%$ variance of perceived value is explained by product quality $(\beta=0.106$; correlation $=0.416)$, with a medium predictor effect on perceived value $\left(\mathrm{f}^{2}=0.179\right)$. The correspondent $t$-student value is 1.529 and the $\mathrm{p}$-value attained is 0.536 . These data are not significant so hypothesis H8 (perceived product quality will have a positive effect on the customer's perceived value) must be rejected. Conversely, the values relating to perceived service quality and perceived value by customers with a $6.42 \%$ explained variance $(\beta=0.173$; correlation $=0.371)$ and a low predictor value on perceived value $\left(f^{2}=0.033\right)$ confirm hypothesis H10 (perceived service quality will have a positive effect on customerperceived value). Therefore, customers' perceived value is well linked with perceived service quality, and with weighted benefits against the price paid for the offered characteristics, taking the experience customers acquire after their wine intake as a reference.

Expectations have a direct, positive and causal relationship with perceived product quality and perceived service quality. The variance for perceived product quality explained by expectations is $38.32 \%$, which is one of the highest variances in the model $(\beta=0.619$; correlation $=0.619)$ and also produces a high predictor effect on perceived product quality. Consequently, hypothesis H6 (expectations created by customers increase the perception of product-perceived quality, result perspective) is accepted. It shows that expectations are changing owing to the experience customers acquire after tasting a wine and also because customers are unable to evaluate organoleptic wine qualities objectively. This helps to improve product quality perception based on past relationships, image and the word-of-mouth relationship.

The influence of perceived service quality is less relevant because expectations only explain $16.16 \%$ of the variance of perceived service quality $(\beta=0.402$; correlation $=$ 0.402 ) and has a medium predictor effect on it. According to the data, hypothesis $\mathrm{H7}$ (expectations created by customers increase the perception of service-perceived quality, functional perception) can be accepted. Perceived service quality is an intangible and formulated concept relating to customer perception that satisfies expectations. Expectations have only one previous variable, image, which can explain the $18.75 \%$ of the expectation variance $(\beta=0.433$; correlation $=0.433)$ and which generates an average predictor effect on expectations $\left(\mathrm{f}^{2}=0.231\right)$. Thus, hypothesis H1 (image positively affects wine customer expectations) is supported.

The image customers form represents wine qualities and benefits for themselves. Customers will trust the image before other factors to obtain expectations of a future intake experience. Likewise, the existence of an indirect effect produced by image on satisfaction must be considered, which is performed indirectly through the mediator variable, expectations. 
According to the loyalty variable, the level where one of its previous variables, satisfaction, explains $39.55 \%$ of its variance $(\beta=0.592$; correlation $=0.668)$ corresponds to the highest percentage of the model with a high predictor effect as well $\left(\mathrm{f}^{2}=0,563\right)$. Thus, hypothesis H13 (loyalty is a consequence of customer satisfaction) is sustained. This confirms that there is a positive relationship between satisfaction and repurchase intentions. Satisfaction becomes the main reason for a customer's future intentions, thus acquiring a crucial role in establishing a long-term relationship with customers and, consequently, in achieving company objectives.

Nevertheless, image interferes moderately in customer loyalty formation, since the explained variance by image is $8.11 \%(\beta=0.190$; correlation $=0.427)$ and it also has an average predictor effect on loyalty $\left(f^{2}=0.231\right.$ ), so hypothesis $\mathrm{H} 3$ (the image customers create through wine intake experiences positively affects wine repurchase), is approved. Without any doubt, a well-positioned corporate image in the market generates more customer confidence and strengthens long-term relationships. Satisfaction and perceived image become customer loyalty drivers.

New ECSI DOP Modeling results:

In reference to the results obtained from the evaluation of the structural model, only two of the originally proposed hypotheses must be rejected, hypothesis 2 and hypothesis 8 . $\mathrm{H} 2$ corresponds to the image and satisfaction relationship and $\mathrm{H} 8$ combines product quality and value variables.

The original modeling is redefined unifying perceived product quality and perceived service quality variables in only one construct to imitate the ASCI model. The principal purpose is to adapt and improve the model for use in the wine sector, thus optimizing its predictive capacity. The non-causal relationship between the image and satisfaction variables remains the same as the original ECSI model, since a causal relationship has been shown in the studied literature; therefore, this relationship has to be evaluated again in the new proposed model.

Therefore, the following hypotheses can be confirmed as the same as in the original model.

H1: Image positively affects wine customer expectations.

H2: Image positively affects wine customer satisfaction.

H3: The image customers create through wine intake experiences positively affects wine repurchase.

H4: The confirmation of customers' expectations positively impacts on model satisfaction.

H5: customer expectations positively influence expected benefits from wine intake compared with its price.

H6: Expectations created by customers increase the perception of product-perceived quality.

H7: Perceived quality will have a positive effect on the customer's perceived value.

H8: Perceived customer quality positively influences customer satisfaction.

H9: Perceived value directly influences customer satisfaction.

H10: Loyalty is a consequence of customer satisfaction. 
Figure 4.

ECSI DOP(modified modeling)

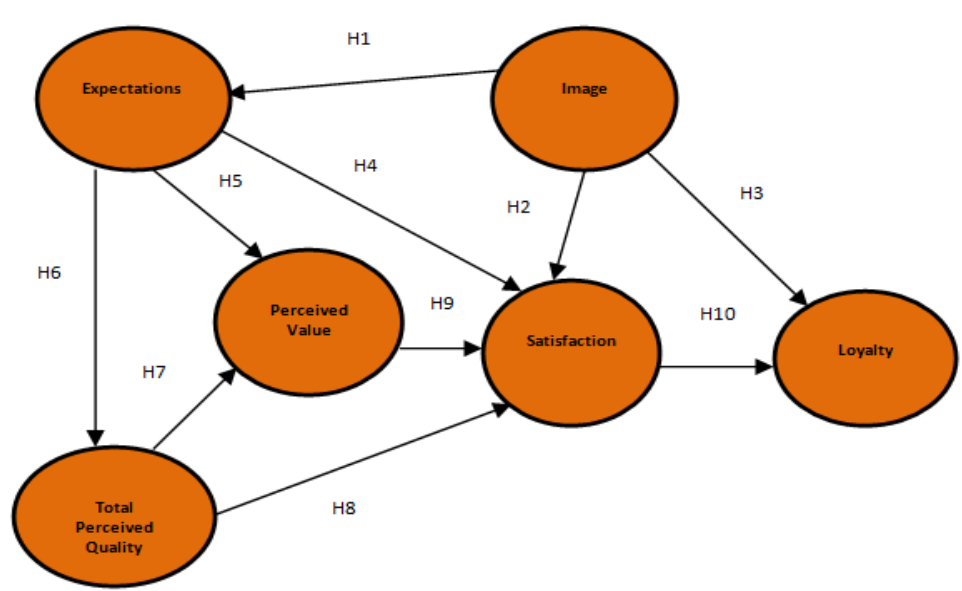

Similarly, as in the previous procedure, firstly, Cronbach's alpha and the composed reliability should be calculated to obtain the reliability of the new model measurement instrument.

According to table VI and in reference to the internal evaluation from the composed reliability and Cronbach's alpha, all the latent variables fulfill the established criterion and so every latent variable is one-dimensional. Moreover, a high reliability of the measurement scales is deduced, with composed reliability values close to 0.9 .

\begin{tabular}{llllr}
\hline Latent Variables & Composed Reliability & Cronbach's Alpha & AVE & \\
\cline { 1 - 2 } Total Quality & 0.865 & 0.818 & 0.517 & \\
Expectations & 0.915 & 0.861 & 0.782 & Table VI. \\
Image & 0.877 & 0.817 & 0.642 & Internal Consistency \\
Loyalty & 0.852 & 0.769 & 0.59 & Evaluation and \\
Satisfaction & 0.885 & 0.826 & 0.658 & Average Variance \\
Value & 0.838 & 0.714 & 0.634 & Extracted, AVE \\
\hline
\end{tabular}

The convergent validity from the Average Variance Extracted (AVE) was calculated. The AVE of each variable should reach more than 0.50 , thus establishing that more than $50 \%$ of the construct variance is interpreted by its indicators, so the model still fulfills the convergence of each variable, as the previous model did.

Discriminant validity was then calculated. It can be observed that the correlation values between the constructs are smaller than the shared average variance among a construct and its measures, so it can be assured that every latent variable fulfills the criterion. Latent variables are, therefore, more correlated with their indicators than with the other latent variables.

\begin{tabular}{|c|c|c|c|c|c|c|c|}
\hline Latent Variables & Total Quality & Expectations & Image & Loyalty & Satisfaction & Value & \\
\hline Total Quality & 0.719 & & & & & & Table VII. \\
\hline Expectations & 0.559 & 0.884 & & & & & Discriminant \\
\hline Image & 0.454 & 0.434 & 0.801 & & & & Validity Evaluation \\
\hline Loyalty & 0.49 & 0.555 & 0.427 & 0.768 & & & Fornell-Larcker \\
\hline Satisfaction & 0.687 & 0.761 & 0.401 & 0.668 & 0.811 & & Criterion \\
\hline Value & 0.47 & 0.51 & 0.22 & 0.287 & 0.542 & 0.796 & ECSI DOP \\
\hline
\end{tabular}

After asserting the reliability of the new model, the structural model is then resolved. Firstly, $\mathrm{R}^{2}$ shows the variance quantity of the construct, which is explained by the model. 


\begin{tabular}{|c|c|c|c|}
\hline Latent Variables & $\mathbf{R}^{2}$ & Communality & \\
\hline Total Quality & 0.313 & 0.517 & \\
\hline Expectations & 0.189 & 0.782 & \\
\hline Image & & 0.642 & \\
\hline Loyalty & 0.476 & 0.59 & Table VIII. \\
\hline Satisfaction & 0.688 & 0.658 & $\mathrm{R}^{2}$ Endogenous \\
\hline Value & 0.31 & 0.634 & Latent Variables \\
\hline GoF & & & ECSI DOP \\
\hline
\end{tabular}

Likewise, $68.8 \%$ of the satisfaction variance was interpreted by the four previous constructs and almost $47.6 \%$ of the loyalty variable is explained by the satisfaction and image constructs. In contrast, communality values are over 0.5 , which means the model has predictive validity. Later, the size effect $\mathrm{f}^{2}$ of each latent variable was assessed.

\begin{tabular}{|c|c|c|c|c|c|c|c|}
\hline Latent Variables & Total Quality & Expectations & Image & Loyalty & Satisfaction & Value & \\
\hline Total Quality & & & & & 0.227 & 0.072 & \\
\hline Expectations & 0.456 & & & & 0.466 & 0.128 & \\
\hline $\begin{array}{l}\text { Image } \\
\text { Loyalty }\end{array}$ & & 32 & & 0.057 & 0 & & $\begin{array}{r}\text { Table IX. } \\
\text { Size Effect } \mathrm{f}^{2}\end{array}$ \\
\hline Satisfaction & & & & 0.561 & & & Latent Variables \\
\hline Value & & 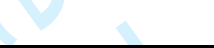 & & & 0.032 & & ECSI DOP \\
\hline
\end{tabular}

On evaluating the $\mathrm{f}^{2}$ values previously listed in table IX, it was observed that the relationships with a high predictor effect correspond to the relationships between expectations with total quality, expectations with satisfaction and loyalty with satisfaction. The relationships between total quality and satisfaction, and image and expectations have an average predictor effect. The other relationships have a low predictor effect, except the relationship between image and satisfaction, which resulted null. A predictor increase between the total quality variable with value appeared after the model modification.

\begin{tabular}{|c|c|c|c|c|c|c|c|}
\hline Latent Variable & T-Student & p-value & $\begin{array}{l}\text { Path } \\
\text { Coefficient } \\
\text { (及) }\end{array}$ & $\begin{array}{l}\text { Variables } \\
\text { Correlation }\end{array}$ & $\mathrm{B} * \mathrm{CV}$ & $\begin{array}{l}\text { Variance B } \\
\text { explained by A }\end{array}$ & \\
\hline Total Quality -> Satisfaction & 7.521 & 0 & 0.348 & 0.687 & 0.239 & $23.90 \%$ & Table VII. \\
\hline Total Quality-> Value & 3.915 & 0 & 0.27 & 0.47 & 0.127 & $12.70 \%$ & t-student, \\
\hline Expectations -> Total Quality & 10.238 & 0 & 0.559 & 0.559 & 0.313 & $31.30 \%$ & p-value and \\
\hline Expectations -> Satisfaction & 8.72 & 0 & 0.505 & 0.761 & 0.384 & $38.40 \%$ & path \\
\hline Expectations -> Value & 4.792 & 0 & 0.359 & 0.51 & 0.183 & $18.30 \%$ & coefficients, \\
\hline Image -> Expectations & 7.487 & 0 & 0.434 & 0.434 & 0.188 & $18.80 \%$ & \% variance b \\
\hline Image -> Loyalty & 3.445 & 0.001 & 0.189 & 0.555 & 0.105 & $10.50 \%$ & explained \\
\hline Image $->$ Satisfaction & 0.112 & 0.91 & -0.003 & 0.401 & 0.001 & $0.10 \%$ & by the \\
\hline Satisfaction -> Loyalty & 10.95 & 0 & 0.592 & 0.668 & 0.395 & $39.50 \%$ & latent \\
\hline Value -> Satisfaction & 2.27 & 0.023 & 0.122 & 0.542 & 0.066 & $6.60 \%$ & variables \\
\hline
\end{tabular}

Afterwards, the bootstrapping resampling method and the t-student values were evaluated. T-student values over 1.98 show that the relationships with two-tailed test are significant, and if they are over 0.99 , this indicates they are significant with only onetailed test. Besides, if a p-value is smaller than the significant level, established as $\alpha=0.05$, rejecting a null hypothesis when it is true can be avoided. In reference to table $\mathrm{X}$, all t-student values corresponding to the relationships between the variables are statistically significant, except the relationship between image and 
satisfaction with a 0.112 value, which is under the established 1.98 and shows a p-value over 0.05. It is important to highlight the increase in the values obtained in the new relationship defined between the total quality variable and value with a 3.915 t-student value and a p-value under 0.05 . Therefore, data permit us to appreciate a causal relationship between statistically significant variables.

Each endogenous variable contribution is determined from the path coefficients of the structural model, which comes from the multiplication between the path coefficient and the correlation coefficient among each variable and the endogenous variables. An increase in path coefficients can also be distinguished, highlighting the impact of expectations on total quality with a 0.559 value, expectations on satisfaction with a 0.505 value and the relationship between satisfaction and loyalty with a 0.592 impact. Furthermore, there is an increase in the impact of total quality on satisfaction after unifying quality variables, service and product into only one variable, reaching 0.348 of its weight, and it represents some of the most important data in this new model. Finally, similar to the previous model, the image impact with satisfaction is also null and represents a -0.003 value.

If the Chin (1998) values referred to above are considered, namely that standardized path coefficients should, at least, reach a 0.2 value, and ideally over 0.3 to establish themselves as significant, out of the 10 relationships between the modified model variables, only three are not significant.

In the present study, as in the original model, it is more appropriate to apply the empirical rule proposed by Falk and Miller, whereby a predictor variable should explain at least $1.5 \%$ of the variance in a predicted variable. All the relationships are over the established threshold except for the relationship between image and satisfaction with a $0.1 \%$ value, with the result that it is not significant, as in the original model. With reference to the blindfolding procedure, analyzing the redundancy of crossvalidation (CV) for each latent variable (total quality (0.137), expectations (0.141), loyalty (0.272), satisfaction (0.439), loyalty (0.272), satisfaction (0.439), value (0.175)), we can conclude that each variable represents a predictive relevance because the CV value is larger than zero in all the latent variables. Furthermore, the GoF value, calculated in table VIII, is 0.50 . Thus, we can conclude that the model has a good adjustment, with high overall efficiency and the defined variables explain the model perfectly.

\section{New Model Discussion:}

According to the values obtained after the new structural model evaluation of the ECSI model in relation to DO Somontano wines, it shows that only hypothesis 2 must be rejected out of the 10 proposed hypotheses. This corresponds to the relationship between image and satisfaction, as occurred in the original model. Likewise, the hypothesis linking total quality with value has already been accepted.

Hypothesis 2, which related the image variable to satisfaction, establishes a 0.401 correlation coefficient that is positive and significant, with a practically null path coefficient $(\beta=-0.003)$ and a 0.112 t-student value that is almost zero. Besides, the predictor effect on the variable is also null $\left(\mathrm{f}^{2}=0\right)$ and thus non-significant. Therefore, the satisfaction variance explained by image is also null. That is why the data do not permit us to appreciate a causal relationship between the variables and the hypothesis. Image positively affects wine customer satisfaction must be removed. Conversely, hypothesis 7 (perceived quality will have a positive effect on customerperceived value), which previously had to be rejected (hypothesis 8, which links product quality with value) has a 0.470 correlation coefficient that is positive and 
significant. The new path coefficient estimates a 0.270 value and the t-student is 3.915 , which is statistically significant. Moreover, the $12.70 \%$ of the value variance is explained by quality and has a low predictor effect on perceived value $\left(f^{2}=0.072\right)$. Therefore, in reference to the results, hypothesis 7 is now accepted, confirming the causal relationship between quality and value.

According to the quality latent variable, in relation to the analysis of the external weights, two of its indicators (information conveyed on quality and product accessibility) are lower than the 0.707 desirable value. Therefore, the formulation of the two aforementioned indicators should be reviewed to estimate that the information obtained from them is relevant to measure and evaluate the quality variable. On the contrary, if more important advances are considered to exist, the actual indicators could be replaced in further research.

Regarding standardized path coefficients, the results are very similar and the behavior in the impact order is almost equal in the two estimations. Although the quality impact on value was too low in the original model estimation, as was the service quality impact on value, it is lower than the established threshold in the validated criterion. Conversely, in the new ECSI model, the quality impact on value improves substantially, thus improving model optimization by combining two quality variables into only one. The $\mathrm{R}^{2}$ indicators show a moderate adjustment in both models and the GoF confirms that the overall efficiency is high; therefore, the defined variables can explain these models properly.

\section{Conclusions}

As a result of the present research, a model developed and adapted by European Satisfaction Customer Index has been proposed for the wine sector, specifically targeted at DO wines. This model comprises four previous satisfaction variables, namely image, expectations, perceived value, total perceived quality and loyalty, which is a consequent variable of satisfaction. A significant input on customer satisfaction theories and the analysis of DO wine customer behavior are provided by the proposed model. In this article, model validity has been confirmed, as have the steps followed for its resolution, starting by focusing on the characterization of the variables belonging to this model and its application, which is the purpose of this research.

Pragmatically, the results we have obtained and shown provide a tool that can establish many conclusions for direct use by companies in the sector and that should help them understand their customers' needs and desires better. At the same time, it should facilitate their expectation and perception management and reduce false perceptions or slanted expectations, thus improving a company's chances of achieving customer satisfaction.

With the help of the empirical model analysis, the DO Somontano can learn the importance of customer expectations and perceived quality, which is one of the two most influential factors to achieve satisfaction. Therefore, the DO must give importance to complying with the rules imposed by the Spanish government and ISO standards to generate more value for this collective brand, although it should not underestimate the other variables when the customer satisfaction rate is to be predicted.

The strong relationship between expectations and satisfaction is remarkable and it leads us to assert the predominance of the assimilation phenomenon as opposed to the contrary effect on interpreting satisfaction in the wine sector. The high levels of customer ignorance and insecurity when choosing wine and the subsequent evaluation of it, as well as their emotional character, strengthen the importance of expectations in the modeling of their satisfaction judgment. When this judgment is formed, customers 
are more confident in their expectations or convictions than in their judgments after their wine intake experiences. Consequently, it is difficult for customers to evaluate a product that is becoming increasingly complex and has a high emotional and sensory load.

The analysis also indicates the strong existing relationship between expectations and perceived quality, thus demonstrating that quality perceptions arising from customer expectation determine the perceived result. This demonstration leads us to suggest that the products and services designed by the companies should try to contain mainly features or attributes that customers perceive as rewarding. In the present situation, corporate image does not significantly influence customer satisfaction. Nevertheless, it does have an important indirect effect on satisfaction through expectations as a mediator variable. Likewise, in the proposed model, considering the satisfaction of all customers has a direct and positive effect on loyalty. However, although satisfaction is a necessary condition, it does not suffice to achieve customer loyalty and image plays an important role in the present case. Therefore, maintaining a good corporate image in the market is required to generate confidence in the customer and also to establish long-term relationships. It is also important to realize that attracting a new customer is more expensive than keeping an existing one, and, therefore, customer loyalty should be bolstered to ensure the company's present and future viability.

If the new proposed model is compared with the original, the obtained data are similar, except for the relationship between perceived total quality and perceived valueaccepting the previously rejected hypothesis - and satisfaction, which improved notably as expected. The relationships between expectations and perceived total quality and satisfaction, including the relationship between satisfaction and loyalty, are more relevant than in the original model. Besides, as mentioned above, the hypothesis that links image with satisfaction was discarded.

An important and interesting new ECSI model contribution for the wine sector with respect to the previous one has been highlighted in this paper. The service and product qualities are linked in a unique variable, total quality, since the preference is for the satisfaction level to be evaluated from a more all-encompassing perspective within the wine sector.

Since the ECSI model has not been implemented previously to study the satisfaction of DO wine consumers, it is a great opportunity for DO Somontano to apply this acquired knowledge to better meet the needs of its potential customers.

According to the data collected in this article, the proposals arising from the measurement of satisfaction are that DO Somontano should invest in sophisticated techniques and in R\&D to increase the quality of its wines and also in appropriate and shocking advertisements, amazing and useful gifts for a loyal customer and premium prizes for expanding its image in customers to upgrade their expectations.

Likewise, an improvement in the value of DO Somontano's collective brand would have an important economic impact on the society in this region as it would create more jobs in Somontano's wine industry, which would be promoted as a recognized place for wine tourism, thus establishing more negotiations with the Somontano area, leading to more investments.

In summary, if DO Somontano wishes to stand out from other wine collective brands, it should differentiate itself from its competitors by spending part of its profits on innovation and on improving its brand perception. 


\section{References}

Anderson Eugene W., Fornell, Claes and. Lehmann Donald R., (1994). Customer Satisfaction, Market Share, and Profitability: Findings from Sweden. Journal of Marketing. Vol. 58, No. 3, pp. 53-66.

Anderson, E. W. and Sullivan, M. (1993). The Antecedents and Consequences of Customer Satisfaction for Firms, Marketing Science 12, 125-143.

Anderson, E.W. and Fornell, C. (1994). A customer satisfaction research prospectus. Service Quality: New Dimensions in Theory and Practice. Rust, R.T. and Oliver, R.L. (eds.), Sage CA, pp. 241-268.

Anderson, E.W. and Fornell, C. (2000). Foundations of the American Customer Satisfaction Index, Total Quality Management 11, S869-S882.

Andreassen, T. W. and Lindestad, B. (1998). Customer loyalty and complex services: The impact of corporate image on quality, customer satisfaction and loyalty for customers with varying degrees of service expertise. International Journal of Service Industry Management 9, 7-23.

Askariazad, Mohammad Hossein, Babakhani, Nazila (2015). An application of European Customer Satisfaction Index (ECSI) in business to business (B2B) context. Journal Of Business \& Industrial Marketing 30, 17-31.

Cassel, C. and Eklof, J.A. (2001) Modeling customer satisfaction and loyalty on aggregate levels: experience from the ECSI pilot study. Total Quality Management, 12, 7-8, pp. 834-841.

Cohen, J., Cohen, P., West, S. G., \& Aiken, L. S. (2003). Applied Multiple Regression/Correlation Analysis for the Behavioral Science (3 ed.). New Jersey: Lawrence Erlbaum Associates. Inc.

Chin, W.W. (1998): “The Partial Least Squares Approach to Structural Equation Modeling”, en G.A. Marcoulides [ed.]: Modern Methods for Business Research, pp. 295-336. Mahwah, NJ: Lawrence Erlbaum Associates, Publisher.

Chin, W.W.; (2004): PLS-Graph. Version 3.00. build 1060. University of Houston, Texas, USA.

Chin, W.W.; Newsted, P.R. (1999): Structural Equation Modeling Analysis with Small Samples Using Partial Least Squares, en R. Hoyle [ed.]: Statistical Strategies for Small Samples Research, pp. 307-341. Sage Publications.

Constanza Bianchi; Judy Drennan and Bill Proud. Antecedents of consumer brand loyalty in the Australian wine industry; Journal of Wine Research, volume 25, 2014

Constanza Bianchi; Consumer Brand Loyalty in the Chilean wine industry. Journal of Food products marketing. Volume 21, 2015.

Eklöf, J.A. (2000). European Customer Satisfaction Index. Pan-European telecommunication sector report based on the pilot studies 1999. Stockholm: European Organization for Quality and European Foundation for Quality Management.

Enrico Ciavolino \& Jens J. Dahlgaard (2007) ECSI - Customer Satisfaction Modelling and Analysis: A Case Study, Total Quality Management \& Business Excellence 18:5, 545-554

Ferreira, I. ; Cabral, J. ; Saraiva, P. (2010) An integrated framework based on the ECSI approach to link mould customers' satisfaction and product design. Total Quality Management \& Business Excellence 21:12, 1383-1401.

Fornell, C. (1982): A Second Generation of Multivariate Analysis: An Overview, en C. Fornell [ed.]: A Second Generation of Multivariate Analysis, 1: 1-21. New York: Praeger Publishers. 
Fornell, C.; Bookstein, F.L. (1982): A Comparative Analysis of Two Structural Equation Models: Lisrel and PLS Applied to Market Data, en C. Fornell [ed.]: A Second Generation of Multivariate Analysis, 1: 289-324. New York: Praeger Publishers.

Fornell, C.; Johnson, M. D.; Anderson, E. W.; Cha, J.; and Bryant, B. E. (1996). The American Customer Satisfaction Index: Nature, purpose, and findings. Journal of Marketing, 60 (4), 7-18.

Haenlein M., Kaplan A. (2004). A beginner's Guide to Partial Least Squares Analysis. Understanding Statistics 3, 283-297.

Hair, Jr., J. F., Black, W. C., Babin, B. J., Anderson, R. E., \& Tatham, R. L., 2006. Multivariate Data Analysis (6th ed.). Upper Saddle River, NJ: Pearson Prentice Hall.

Henseler J, Ringle C. M. \& Sinkovics R. R.,(2009). The use of Partial Least Squares Path Modeling in International Marketing. Advances in International Marketing, Vol. 20, 277-319.

Johnson, M. D., Anderson, E. W., \& Fornell, C. (1995). Rational and adaptive performance expectations in a customer satisfaction framework. Journal of Consumer Research, 21(4), 695-707.

Johnson, M. D., Gustafsson, A., Andreassen, T. W., Lervik, L. and Cha, J. (2001). The Evolution and Future of National Customer Satisfaction Index Models, Journal of Economic Psychology 22, 217-245.

Johnson, M.; Anderson, E. W.; Fornell, C. (1995). Rational and adaptive performance expectations in a customer satisfaction framework. Journal of Consumer Research, 21 (March), 695-707.

Kristenensen, K., Martensen, A., and Gronholdt, L: (1999). Measuring the impact of buying behavior on customer satisfaction. Total Quality Management, 10(4-5), 602-614.

Martensen, A., Grønholdt, L. and Kristensen, K. (2000). The Drivers of Customer Satisfaction and Loyalty, Cross-Industry Findings From Denmark, Total Quality Management 11, 8544-8553.

Mojtaba Kaveh, Seyed Alireza Mosavi and Mahnoosh Ghaedi. The application of European customer satisfaction index (ECSI) model in determining the antecedents of satisfaction, trust and repurchase intention in five-star hotels in Shiraz, Iran, African Journal of Business Management Vol. 6(1), pp. 6103-6113, 16 May, 2012.

Oliver, R.L. (1980). A cognitive model of the antecedents and consequences of satisfaction decisions. Journal of Marketing Research, 27, 460-469.

Santiago Ospina Pinzón and Irene Gil Saura (2011), National index of consumer satisfaction. A proposal for a review of literature, Cuad.Adm. vol.24 no.43 Bogotá July/Dec. 2011.

Tenenhaus M. (2008). Component-based Structural Equation Modeling. Total Quality Management \& Business Excellence Vol. 19, No. 7\&8. P. 87-886.

Tenenhaus, M. (2003). Comparison between PLS and LISREL approaches for structural equation modeling: application to the measure of Customer Satisfaction. PLS'03 "Focus on customer" - PLSand related methods, Lisbon, Decisia.

Woodruff, R.B.; Schumann, D.W. and Gardial, S.F. (1993). Understanding value and satisfaction from the customer's point of view. Survey of Business, vol. 28 (Verano/Otoño), pp. 33-40. 
Yuan Jingxue, Alastair Morrison, Liping Cai and Sally Linton; A model of wine tourist behaviour: a festival approach. International Journal of Tourism Research, 25 february 2008 


\section{Validation and Improvement of the European Customer Satisfaction Index for the Spanish Wine Sector}

Purpose: A study of the Spanish wine sector, in this case specifically the Designation of Origin (DO) Somontano, requires validation of the European Customer Satisfaction Index (ECSI), which also needs to be improved and adapted to obtain more information on customer satisfaction.

Design/methodology/approach: Applying the ECSI model, based on structural equation modeling (SEM) using partial least squares (PLS).

Findings: An empirical analysis shows that the importance of customers' expectations and perceived quality are the most influential factors in achieving satisfaction. Also highlighted in the new model is the linkage between service and product qualities in a unique variable, total quality.

Originality/value: In addition to validating the ECSI model for DO Somontano, a new innovative implementation was developed and tested to improve the calculation of satisfaction.

Keywords: Customer satisfaction, quality management, organizational structure, value analysis, corporate image, customer loyalty 


\section{Introduction}

In order to obtain greater benefits all the wine companies desire to know how can they quantify the customer satisfaction with the purpose of acquiring a strategic advantage with their competitors. One of the most effective way to carry it out is through an econometric study. Therefore, enterprises design different measurement tools that allow them to comprehend the customer satisfaction indexes. An evaluation and analysis of these satisfaction indexes constitute an indispensable mechanism to measure the customer's needs.

Over the years, many authors have studied customer satisfaction and what it represents. One of the most important author was Oliver (1980). He explained the satisfaction as a feeling that comes from one or several experiences and he is also in agreement with Woodruff and Gardial (1991). A different theory was proposed by Fornell, Anderson, Lehmann and Johnson (1995), the satisfaction represents the overall evaluation of the accumulative experience that customers obtain while they are using or trying the product and/or service over time. Croning and Taylor (1994) and Jones and Suh (2000) suggested that satisfaction is an accumulative evaluation and, consequently, represents an overall judgment rather than a specific transaction review. Therefore, based on this double perspective (specific transaction and accumulative vision), the analysis of satisfaction stands out for its business impact and it can be introduced in the wine sector.

An analysis from an accumulative point of view allows us to understand satisfaction as an important indicator in the global market (macroeconomic view) and in each company (microeconomic view), since profits and product and/or service results are evaluated from customers' use over a long period of time (Anderson and Fornell, 1994; Oliver, 1997).

Customer satisfaction analysis has attained more importance since the 1980s due to an increase in competition and service sector development. Consequently, several countries have designed and implemented national indexes to measure customer satisfaction. These indexes, besides obtaining the level of clients satisfaction, also allow to interpret which are the indicators that are involved in the acquisition of the satisfaction that are able to anticipate the future clients' demands and also to evaluate the effectiveness of the strategies applied. The most famous and pragmatic indexes are the American Customer Satisfaction Index (ACSI) and the Swedish Customer Satisfaction Barometer (SCSB) developed by Fornell, the Deutsche Kundenbarometer (DK) created by Eklöf, the Norwegian Customer Satisfaction Barometer (NCSB) established in 1998 by Andreassen and Lindestad and the European Customer Satisfaction Index (ECSI) studied by Eklöf in 2000 which is used in our study. These indexes are proposed to value customer satisfaction under the accumulative satisfaction view with the purpose of measuring customer satisfaction ranks through variables formed when a product or service is utilized (Fornell et al., 1996).

When a product is marketed, companies should know which guidelines must be followed to obtain a better customer satisfaction. One of the most precise method for estimating customer satisfaction is the ECSI model, based on a structural model (SEM) and validated through a partial least squares (PLS) statistical method, the SmartPLS3. In 
this research, another new model, which accepts every improvement, has been designed to deliver more accuracy.

\section{Theoretical Approach}

\section{Literature Review}

There are not many articles related with the wine customer satisfaction. In the research carried out by Costanza Bianchi "Precedents of consumer brand loyalty in the Australian wine industry" (2014) and "Consumer Brand Loyalty in the Chilean Wine Industry (2015)", loyalty has been explained through an econometric model. She proposed a conceptual SEM model of consumer brand loyalty with five different latent variables: Wine knowledge, wine experience, wine brand satisfaction, wine brand trust and wine brand loyalty. Our study will focus on getting satisfaction because loyalty is its consequence.

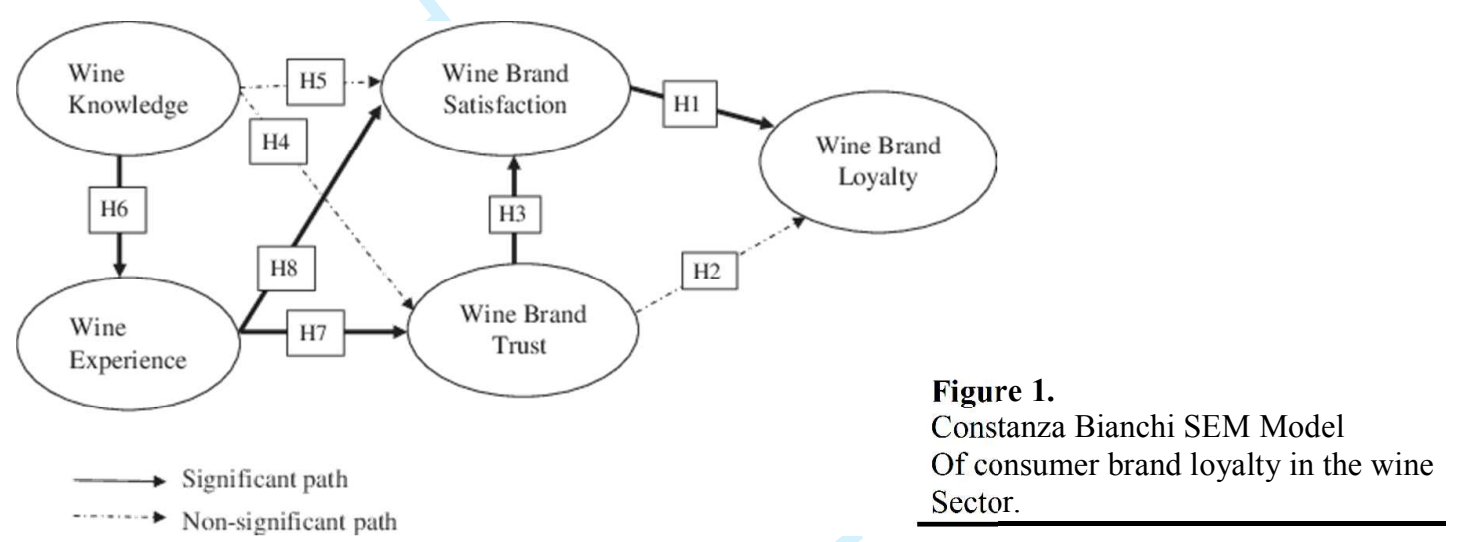

The main difference between our studies is the lack of expectations and satisfaction that the brand generates in the consumers through its image, in other words, it needs greater implication of the Denomination of Origin to attract new consumers through its wine prices and quality with an appropriate Marketing strategy.

Other related article is the Jingxue Yuan research (2018): "A model of wine tourist behaviour: a festival approach", which determined a temporal model of wine tourists behaviour according to the consumer attitudes and related concepts with regard to past behaviour, satisfaction, perceived value and behavioural intentions.

Most ECSI model researches have been used to establish customer satisfaction based on SEM and estimated through PLS. For example, four studies have been conducted in this area of knowledge: 'The application of European Customer Satisfaction Index (ECSI) model in determining the antecedents of satisfaction, trust and repurchase intention in five-star hotels in Shiraz, Iran' written by Mojtaba Kaveh, Seyed Alireza Mosavi and Mahnoosh Ghaedi (2012); 'ECSI - Customer Satisfaction Modelling and Analysis: A Case Study' by Enrico Ciavolino and Jens J. Dahlgaard (2007); 'An integrated framework based on the ECSI approach to link mould customers' satisfaction and product design' by Irene Ferreira, José Cabral and Pedro Saraiva (2010); and 'An application of European Customer Satisfaction Index (ECSI) in business to business (B2B) context' by Mohammad Hossein Askariazad and Nazila Babakhani (2015). 
The shortage of articles that analyze customer satisfaction from the structural model of the variables belonging to the ECSI model has allowed us to obtain innovations about the importance of satisfaction in a collective brand such as Designation of Origin (DO) wines. Furthermore, this research has presented a new ECSI model for obtaining DO customer satisfaction with better results.

\section{Proposed Methodology}

DO Somontano wines belong to a collective mark, which is why an ECSI model can be performed to analyze customer satisfaction of a wine group produced in the same region and not only for a specific Somontano wine brand. Therefore, in this article, the ECSI model is utilized to evaluate customer satisfaction of DO (Designation of Origin) Somontano wines, optimizing its predictive capacity. The variance analysis is developed for the PLS algorithm (Chin, 1998), using smartPLS as a study tool.

\section{European Customer Satisfaction Index}

Several countries have developed National Satisfaction Indexes, based on structural equation models (SEM), which help to achieve the causal analysis of the different variables involved in the structural models and determine the amount of client satisfaction, this variables influence on satisfaction so they are a consequence of customer satisfaction or dissatisfaction from the consumption of a product and service. "The success of the application of the Swedish and American indexes to evaluate customer satisfaction, which included the European Organization for Quality (EOQ), the European Foundation for the Quality Management (EFQM) and a group of European academic experts who formed the ECSI technical committee, in charge of setting the theoretical basis of the model and developing its methodology and requirements "(Eklöf, 2000).

The European customer satisfaction index represents another alternative of the ACSI model (Eklöf, 2000). "Customer expectations, perceived quality, perceived value, customer satisfaction, and customer loyalty structures are the same as in the ACSI model. As well as indicators for evaluating variables and their causal relationships, except in indicators designed to evaluate loyalty. The European model assesses the probability of retention, the possibility of recommending the company or brand and the likelihood of increased consumption of the product and / or service."

The seven ECSI variables intervening in the estimated model are latent variables that can only be measured indirectly with their indicators or manifested variables. The design used for evaluating the model was determined by the ECSI technical committee, based on Swedish and American indicators, by developing a multi-item questionnaire for collecting customer information (Coelho and Esteves, 2007). The utilization of questions or multiple items for reviewing these variables increases the estimated model precision. Moreover, in the questionnaire design, generic questions or items are used to allow a higher degree of flexibility when this structural model is applied in a different product or service sector (Tenenhaus, 2008). As seen before, satisfaction is the latent variable to be studied and it is related to the model's other six latent variables or qualities which belongs to the product or service. These qualities are formed by value, image, expectations, loyalty and quality, which is divided into perceived quality of product and the perceived quality of service. 


\section{Perceived Quality}

Perceived quality is the extent of the discrepancy between customer expectations or wishes (expected service) and their perceptions (perceived service). Furthermore, quality is whatever customers say it is, in other words, product or service quality arises from every single customer perception after each product or service use. Likewise, we must realize that quality consist on a long-range overall evaluation of the products or services provided to customers (Anderson and Fornell, 1994). In the study of perceived quality, this variable is sometimes divided into two different variables to evaluate other perspectives; the technical or result view and the functional or process perspective. Analyzed quality from a result perspective is called Quality 1, hardware-perceived quality or product-perceived quality. Meanwhile, if it is evaluated from a functional perspective, it is called Quality 2, humanware-perceived quality or service-perceived quality. This distinction between service quality and product quality is a distinguished feature of the ECSI model (Eklöf et al., 2000) and (Kristensen et al., 1999). This shows that product- and service-perceived qualities have a direct and positive causal relationship in customer satisfaction related to ECSI application.

\section{Value}

Zeithaml (1988) defined the concept of perceived value as an overall evaluation of how customers categorize a product based on their perceptions. In other words, according to Lam (2004), it could be considered as customer benefits received from total costs. The price must be included in all assembly expenses (Andreassen and Lindestad, 1998), as must other psychological or derivative costs from the customer effort (Oliver, 1997). Furthermore, Anderson, Fornell and Lehmann (1994) pointed out that perceived value is linked to product- and/or service-perceived quality and the price spent on it. Therefore, value is also defined as the quality-price relationship. When an increment is expected in both variables, it leads to an increase in each customer's satisfaction. It also provides important information on customer perception of the product and/or service, because price is a significant component of perceived value and it is considered one of the most important drivers of satisfaction.

\section{Image}

In reference to Andreassen and Lindestad (1998), image is the reputation of the company, product and/or service offered to the customer. It is formed and established in the customer's mind through communication with potential customers and the experience they acquire of product and/or service use whenever they are satisfied with the product and/or service. As this image improves, so does the excellence of the organization. Similarly, image has a direct, causal and positive relationship with customer satisfaction, focusing directly on customer loyalty. Martensen (2000) realized that image influences positively on customer expectations and product and/or service values traded by the company. In this study, corporate image is a previous variable of satisfaction and it also has a causal relationship with other model variables, such as expectations and loyalty.

\section{Expectations}

Customers create expectations of the product or service in a previous shopping stage and the consumer experience then comparatively judges the result and its initial expectations to analyze if there is a positive or negative disagreement. Oliver (1980) posited that if the resultant perception exceeds expectations and is positive, the customer will be satisfied with the product or service. Therefore, expectations will have 
a causal and direct relationship over this perceived product or service, and over the product and/or service value, positively influencing the satisfaction of customer perception.

\section{Loyalty}

Oliver (1997) defined loyalty as deep customer commitment to repurchase the same product, brand or service consistently in future, in spite of situational and marketing influences that may have enough potential to produce a behavioral change in the customer.

Loyalty is the final variable representing the efficiency of a model. If customer loyalty rises, future profits are assured, supporting the quality levels of the company's product and/or service. Moreover, word-of-mouth communication by satisfied customers loyal to the company improves its global prestige, reducing necessary investment in attracting new customers (Anderson and Fornell, 2000).

Customer loyalty can be measured through repeat purchase intention and customer sensitivity to price variations in the future. Image and satisfaction are variables with a direct and positive causal relationship with customer loyalty. Finally, loyalty stands out as the consequence of model satisfaction, evaluated from two different perspectives. The first is based on customer repeat purchase evaluation, and the second on how price variation can change a decision to purchase another product and/or service.

\section{SEM - Structural Equation Modelling}

SEM is a powerful technique that enables researchers the capability of measuring direct and indirect effects that cannot be analyzed because they are hypothetical or not directly observable. Referring to the definition of its creator, Sewall Wright (1921), the model is a statistical method in order to estimate strong relationships by using casual assumptions and statistical data. The fundamental characteristic of SEM is the possibility to allow multiple regressions between variables and latent variables and It is referred to these models as a second generation of multivariate analysis (Fornell, 1982).

- $\quad$ PLS-SEM (Variance-based approach). It is a causal modelling approach which maximize the explained variance of the dependent latent constructs (Hair, 2015).

- Small groups of data

- Measurements that not been fully developed

- Theories that not been absolutely developed

- Data with non-normal distribution

$\circ$ The presence of formative and reflective indicators

- Interest in predicting the dependent variable

ECSI Method: ECSI model formulation applied to the wine sector The ECSI method is designed by structural equation modeling (hereinafter SEM) using partial least squares (hereinafter PLS, Eklöf, 2000 and Henseler, Ringle and Sinkovics, 2009) as an estimation medium. Designed to explain causes and effects on customer satisfaction, the structural model also assesses causal relationships between various latent variables prior to satisfaction, corporate image, customer expectations, perceived quality and perceived value. In addition, it can evaluate the existing direct causal relationship between satisfaction and loyalty. The European model contains retention probability, the possibility of recommending the company or trademark and the probability of increasing product and/or service use. This model does not include associated incidences, provided by customers in disagreement with the "complain" variable. If we focus on figure 1, the exogenous latent variables are independent of the 
other variables and they do not receive impacts on the graphic representation as only arrows emerge. The image in the ECSI model is the only variable of this type. By contrast, the other variables in the model are endogenous and dependent on at least one equation of the model. In the graphic representation of the model, endogenous variables are those that receive arrows.

Building on the theoretical development of ECSI latent variables, linked to the conclusions obtained in the evaluated process of the wine sector and the workgroup consisting of DO Somontano experts and researchers from the University of Zaragoza. The following thirteen hypotheses were proposed.

H1: Image positively affects wine customer expectations.

$\mathrm{H} 2$ : Image positively affects wine customer satisfaction.

H3: Image positively affects wine repurchase.

H4: Customer expectations positively impact on model satisfaction.

H5: Customer expectations positively influence expected benefits from wine intake compared with its price.

H6: Expectations created by customers increase the perception of product-perceived quality (result perspective).

H7: Expectations created by customers increase the perception of service-perceived quality (functional perception).

H8: Perceived product quality will have a positive effect on the customer's perceived value.

H9: Perceived customer product quality positively influences customer satisfaction.

H10: Perceived service quality will have a positive effect on customer-perceived value.

H11: Perceived customer-service quality positively influences customer satisfaction.

H12: Perceived value directly influences customer satisfaction.

H13: Loyalty is a consequence of customer satisfaction.

Figure 2.

ECSI Path diagrams, Hypothesis.

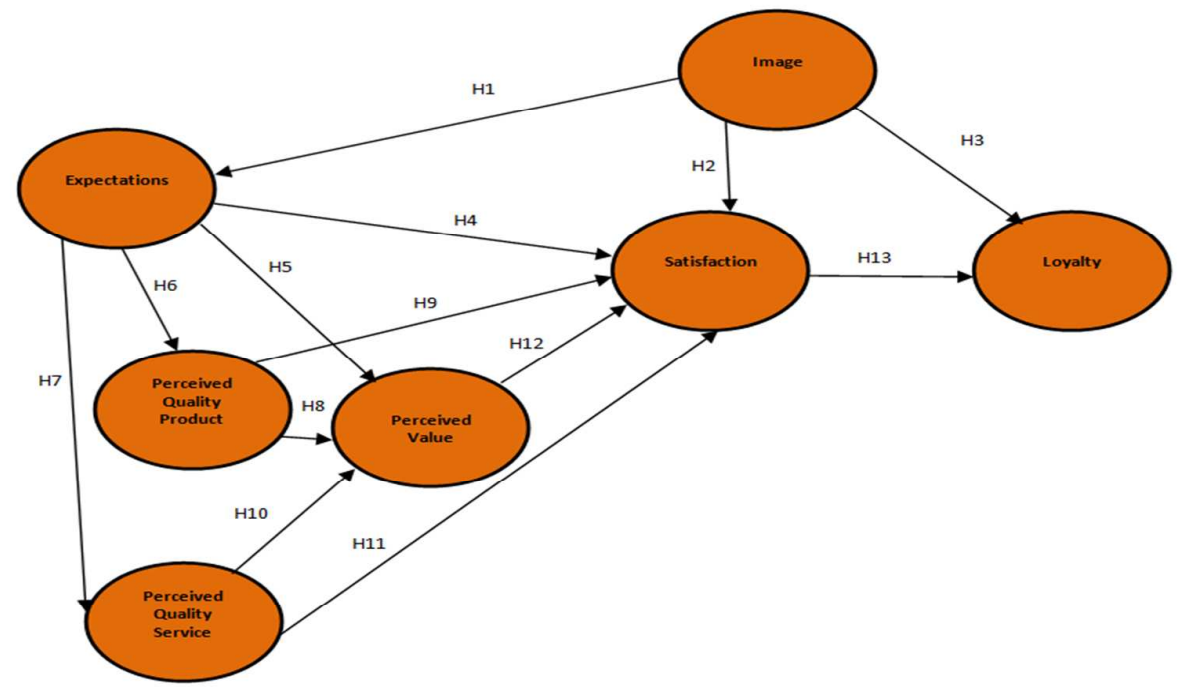

A structural questionnaire winn ciosed answers was aesignea oy using estaonisned standards created by the ECSI committee to associate manifest variables with other latent variables, taking into consideration the recommendations and proposals designed by DO Somontano experts and researchers from the University of Zaragoza. Regarding sample size in the proposed ECSI model, Barclay, Higgins and Thompson (1995) indicated that the latent satisfaction variable is the only one with a higher number of structural paths (six). Therefore, in a PLS estimation, the questionnaire should be 
adequate, in a good way, with a sample of 60 cases $(6 \times 10)$. Cohen says that the G*Power software developed by the University of Kiel in Germany has to be used to delete a null hypothesis when it is false in the potency calculation. Conventionally, an $\alpha$ $=0.05$ and a $\beta=0.20$ are assumed to achieve a proper balance between these types of errors. Concluding on statistics terms, potency is equal to $1-\beta$, so the suitable power level should always be equal or higher to 0.8 (Cohen, 1998).

A sampling with a non-probabilistic method was used, specifically, sampling selection, to extract the population. It was performed through the snowball sampling method. This type of sampling consists of selecting respondents using reference systems through the other respondents. In our study, the questionnaire was distributed to a list of students, professors and university staff of the University of Zaragoza and DO Somontano customers. A link was also published in a Somontano communication group. This type of sample allowed us to know the exact scope of our survey.

The chosen cut point was decided by acquiring sufficient samples that could represent the effect of the sample as medium. Therefore, at least 98 responses must be obtained to achieve sufficient numbers of samples to reach $80 \%$ potency. This number of samples complies with the recommended criterion and proposed modeling in previous research (at least 60 cases). Initially, owing to the temporary limitation of the research, a minimum number of 150 cases was set as a target, which also satisfies the criterion established above. Data collection concluded after 60 days. A total of 244 cases was obtained, of which 170 belonged to wine customers in the DO quality region. The other 74 were not wine drinkers or only drank wine with no designation of origin.

The calculated process of the Cohen power is represented next, but in this case, using the sample size obtained in the data collection as a basis. A $99.9 \%$ potency was obtained from these 244 answers in this sample type. Therefore, the size of the sample sufficed to reach the objectives of the present study.

Figure 3. $\alpha$ and $\beta$ Error for the potency estimation with 6 regressors and 244 inquests

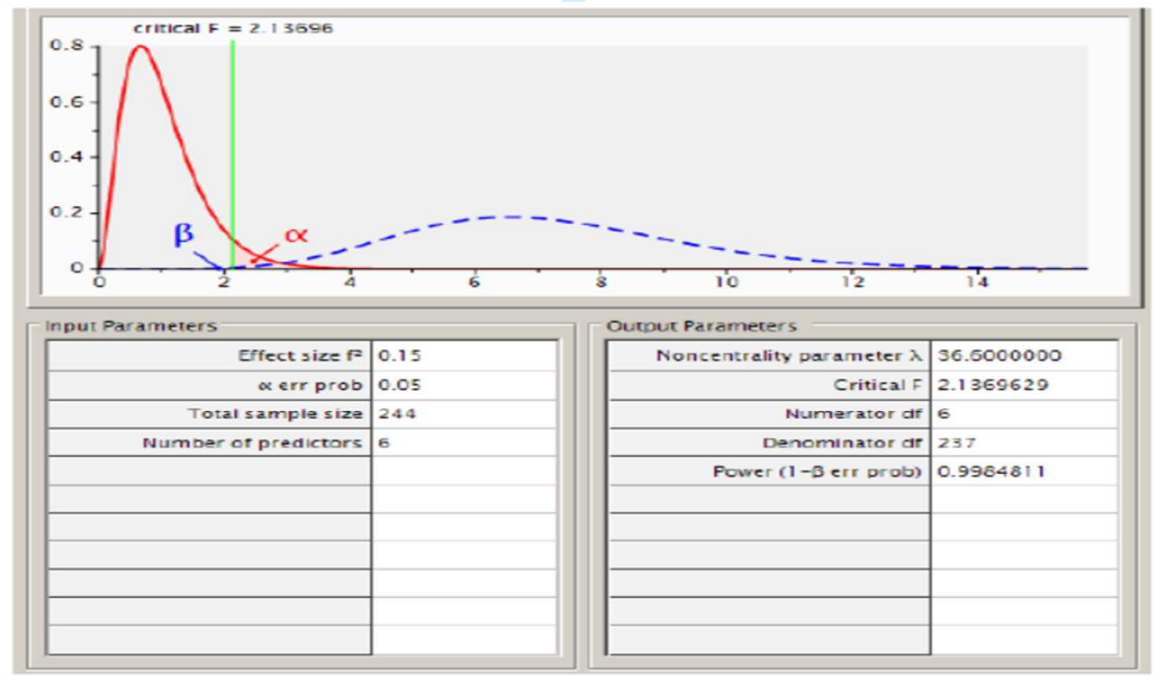

Analysis of the proposed structural model and the hypothesis contrast. Original ECSI model results:

The purpose of this research is to study and verify the factors with the most influence on wine DO customer satisfaction. SEM divided into two parts was used to qualify satisfaction. Firstly, the measure model showing the amount of linkage of the latent 
variables with their indicators. And secondly, the structural model, which highlights the relationship between the other latent variables. It is validated according to a PLS statistical method, the SmartPLS3. The reliability of the measurement model instrument can be observed in the following tables.

\begin{tabular}{|c|c|c|c|c|}
\hline $\begin{array}{l}\text { Latent } \\
\text { Variables }\end{array}$ & $\begin{array}{l}\text { Composed } \\
\text { Reliability }\end{array}$ & $\begin{array}{l}\text { Cronbach's } \\
\text { Alpha }\end{array}$ & AVE & \\
\hline Product Quality & 0.847 & 0.764 & 0.582 & \\
\hline Service Quality & 0.872 & 0.804 & 0.631 & \\
\hline Expectations & 0.915 & 0.861 & 0.782 & \\
\hline Image & 0.877 & 0.817 & 0.642 & Table I. \\
\hline Loyalty & 0.852 & 0.769 & 0.59 & Internal Consistency \\
\hline Satisfaction & 0.884 & 0.826 & 0.658 & Evaluation and Average \\
\hline Value & 0.838 & 0.714 & 0.634 & Variance Extracted, AVE \\
\hline
\end{tabular}

Based on the above table, internal consistency is explained by composed reliability and Cronbach's alpha, where it is indicated that all the latent variables fulfill the established criterion, and, therefore, it is deduced that the measurement scales are extremely reliable, with a composed reliability close to 0.9 .

The average variance extracted (AVE) calculation is recommended to be over 0.50, with this case establishing over $50 \%$ of the construct variance defined by its indicators. The following table details the AVE square root values of the latent variables in its matrix diagonal. Below the diagonal, the existing correlations between the latent variables are shown to obtain the discriminant validity using the Fornell-Larcker criterion.

\begin{tabular}{llllllrr}
\hline Latent Variables & Product Quality & Service Quality & Expectations & Image & Loyalty & Satisfaction & Value \\
\hline Product Quality & $\mathbf{0 . 7 6 3}$ & & & & & \\
Service Quality & 0.457 & $\mathbf{0 . 7 9 4}$ & & & & \\
Expectations & 0.619 & 0.402 & $\mathbf{0 . 8 8 4}$ & & & Table II. \\
Image & 0.34 & 0.427 & 0.433 & $\mathbf{0 . 8 0 1}$ & Discriminant \\
Loyalty & 0.507 & 0.387 & 0.555 & 0.427 & $\mathbf{0 . 7 6 8}$ & validity evaluation, \\
Satisfaction & 0.705 & 0.51 & 0.761 & 0.4 & 0.668 & $\mathbf{0 . 8 1 1}$ & Fornell-Larcker \\
Value & 0.416 & 0.371 & 0.508 & 0.221 & 0.288 & 0.542 & $\mathbf{0 . 7 9 6}$ \\
\hline
\end{tabular}

According to table II, the value correlations between the constructs are smaller than the average variance shared between a construct and its indicators, so it can be confirmed that every latent variable complies with the established criterion. Before evaluating the structural modeling, the multicolinearity of the explicative variables must be examined. This means they must be independent from each other.

After demonstrating the reliability of the model, structural modeling is implemented. This assesses the importance and magnitude of the relationships between the latent variables. Therefore, the quantity of variance explained by each endogenous variable $\left(\mathrm{R}^{2}\right)$, path coefficients $(\beta)$ and the Stone-Geisser $\left(\mathrm{Q}^{2}\right)$ test are determined in the following tables. Chin (1998) classifies the values of the endogenous variables $\mathrm{R}^{2}$ in the PLS estimated models as substantial if values are over 0.67 , moderated if they are over 0.33 and discrete or poor if values are under 0.19 . 


\begin{tabular}{llll}
\hline Latent Variables & $\mathbf{R}^{2}$ & Communality & \\
\hline Product Quality & 0.384 & 0.582 & \\
Service Quality & 0.162 & 0.631 & \\
Expectations & 0.188 & 0.782 & \\
Image & & 0.642 & Table III. \\
Loyalty & 0.477 & 0.59 & $\mathrm{R}^{2}$ Endogenous \\
Satisfaction & 0.701 & 0.658 & Latent Variables \\
Value & 0.298 & 0.634 & \\
GoF & 0.49 & & \\
\hline
\end{tabular}

In accordance with the obtained data, the explained variance of the endogenous variables $\mathrm{R}^{2}$ only reaches qualified values as substantial ones in the satisfaction variable; moderate values for the product quality and loyalty variables and the variances for the other variables are classified as discrete. Likewise, $70 \%$ of the satisfaction variance is acquired by the four previous constructs and $47.8 \%$ of the loyalty variance can be interpreted by the satisfaction and image constructs. Likewise, communality values over 0.5 indicate that the model has predictive validity. According to Falk and Miller, the explained variance of all the endogenous variables $\left(\mathrm{R}^{2}\right)$ results over 0.1 . Therefore, it can be considered that the formulated relationships among latent variables have an acceptable predictive level.

Chin states that if the influence of a particular latent variable over a dependent construct has a significant impact, the size effect $\mathrm{f}^{2}$ must be evaluated. The resulting criteria may establish that the predictor could exhibit a low (0.02), medium (0.15) or high (0.35) effect in the structural model (Cohen, 1988).

\begin{tabular}{|c|c|c|c|c|c|c|c|c|}
\hline Latent Variables & Product Quality & $\begin{array}{l}\text { Service } \\
\text { Quality }\end{array}$ & Expectations & Image & Loyalty & Satisfaction & Value & \\
\hline Product Quality & & & & & & 0.179 & 0.009 & \\
\hline Service Quality & & & & & & 0.041 & 0.033 & \\
\hline Expectations & 0.622 & 0.193 & & & & 0.317 & 0.119 & \\
\hline Image & & & 0.231 & & م & 0.001 & & Table IV. \\
\hline Loyalty & & & & & & & & Size effect $\mathrm{f}^{2}$ \\
\hline Satisfaction & & & & & 0.563 & & & Latent \\
\hline Value & & & & & & 0.044 & & Variables \\
\hline
\end{tabular}

Statistical significance must be verified applying the resampling method, bootstrapping and checking the t-student value before considering the size of the path coefficients. The t-student statistic values over 0.99 are useful for a one-tail test. Besides, it is ratified that if a p-value is lower than the level of $\alpha$ signification, established as $\alpha=0.05$, a null hypothesis is not rejected when it is true. 
1

2

3

4

5

6

7

8

9

\begin{tabular}{|c|c|c|c|c|c|c|c|}
\hline Latent Variable & $\begin{array}{l}\text { T- } \\
\text { Student }\end{array}$ & p-value & $\begin{array}{l}\text { Path } \\
\text { Coefficient }(\beta)\end{array}$ & $\begin{array}{l}\text { Variables } \\
\text { Correlation }\end{array}$ & $\mathrm{B} * \mathrm{CV}$ & $\begin{array}{l}\text { Variance B } \\
\text { explained by A }\end{array}$ & \\
\hline Product Quality -> Satisfaction & 6.776 & 0 & 0.309 & 0.705 & 0.21785 & $21.78 \%$ & \\
\hline Product Quality -> Value & 1.529 & 0.127 & 0.106 & 0.416 & 0.0441 & $4.41 \%$ & \\
\hline Service Quality -> Satisfaction & 2.647 & 0.008 & 0.134 & 0.51 & 0.06834 & $6.83 \%$ & \\
\hline Service Quality -> Value & 2.376 & 0.018 & 0.173 & 0.371 & 0.06418 & $6.42 \%$ & Table V. \\
\hline Expectations ->Product Quality & 11.833 & 0 & 0.619 & 0.619 & 0.38316 & $38.32 \%$ & T-Student. \\
\hline Expectations ->Service quality & 6.716 & 0 & 0.402 & 0.402 & 0.1616 & $16.16 \%$ & p-value and \\
\hline Expectations $->$ Satisfaction & 7.302 & 0 & 0.437 & 0.761 & 0.33256 & $33.26 \%$ & path \\
\hline Expectations $->$ Value & 4.262 & 0 & 0.373 & 0.508 & 0.18948 & $18.95 \%$ & coefficients, \\
\hline Image -> Expectations & 7.471 & 0 & 0.433 & 0.433 & 0.18749 & $18.75 \%$ & $\%$ variance $B$ \\
\hline Image -> Loyalty & 3.385 & 0.001 & 0.19 & 0.427 & 0.08113 & $8.11 \%$ & explained \\
\hline Image $->$ Satisfaction & 0.62 & 0.536 & 0.018 & 0.4 & 0.0072 & $0.72 \%$ & by the \\
\hline Satisfaction -> Loyalty & 11.007 & 0 & 0.592 & 0.668 & 0.39546 & $39.55 \%$ & latent \\
\hline Value $->$ Satisfaction & 2.777 & 0.006 & 0.138 & 0.542 & 0.0748 & $7.48 \%$ & variables \\
\hline
\end{tabular}

Referring to table $\mathrm{V}$, all the t-student distribution values correspond to the relationships of each variable, which are statistically significant, excluding the values corresponding to the relationship between the image and satisfaction variables, with a t-student value of 0.620 , which is under the 1.98 established value and with a p-value over 0.05 . This is also seen between product quality and value variables with a $1.529 \mathrm{t}$-student value, under the established 1.98 and with a p-value over 0.05 .

This table also captures the contribution of each endogenous variable that is obtained from the multiplication of the path and correlation coefficient among each variable and the other endogenous variables, which represents the relative magnitude of the statistical relationships proposed in the model.

The impact generated by expectations over product quality is highlighted as the most important relationship in this model with a 0.619 value, followed by the relationship between satisfaction and loyalty with a 0.592 value, as well as the relationships between expectations and satisfaction, expectations and service quality and image and expectations, with this coefficient respectively, $0.437,0.402$, and 0.433 .

Likewise, it is important to note the low impact of the variable image on loyalty with a 0.190 value, especially the null impact that the image variable has on satisfaction with 0.018. Therefore, if the values proposed by Chin (1998) are considered, which indicate that the standard path coefficients must reach at least a 0.2 value, and ideally be over 0.3 , to be significant, six of the 13 relationships between the model variables are not significant.

However, according to the proposition put forward by Falk and Miller (1992), who determined a reasonable contribution of the explained variance in an endogenous construct from other latent variables, obtained by multiplying the path coefficient $(\beta)$ and the correspondent correlation coefficient between both variables, an empirical rule softer than Chin's (1998) proposition was implemented, determining that a predictive variable should explain at least $1.5 \%$ of the variance of two variables.

Therefore, in reference to Falk and Miller, who showed that a predictive variable should explain at least $1.5 \%$ of the variance of a predicted variable, all the relationships of this model exceed the established threshold except the relationship between image and satisfaction, which represents a $0.72 \%$ value.

Another parameter considered for evaluation in the structural model is Stone-Geisser's $\mathrm{Q}^{2}$. This criterion is used to analyze the predictive capacity of the model's latent 
variables, utilizing the blindfolding procedure. The redundancy of the acquired crossvalidation must be analyzed. It is obtained when the prediction is performed by the constructs foretelling the analyzed endogenous variable. If the cross-validation (CV) value acquired in the procedure and according to an endogenous latent variable is larger than zero (especially in cross-validation redundancy instead of CV communality), their explicative variables are considered to provide predictive relevance. The $\mathrm{CV}$ calculated for each variable is as follows: product quality (0.209), service quality $(0.091)$, expectations $(0.141)$, loyalty $(0,272)$, satisfaction $(0.445)$, and value $(0.162)$. Every variable is considered to supply predictive relevance.

Finally, goodness of fit (GoF) is detailed (Chin, based on Tenenhaus's work in the variance approach) in table III, where the efficiency of the measuring model and the structural model are evaluated. Although the quality thresholds are not defined, the value of $0.10,0.25$ and 0.36 corresponds to low, medium and high predictions. The GoF value in our model is 0.49 , so the model has a good adjustment, with a high overall efficiency and the defined variables can explain the model correctly.

\section{Model ECSI Discussion:}

As mentioned above, starting from this recent research on data that can analyze the latent satisfaction variable, it has been observed that its variance can be highly explained from its antecedents. Since the value of $\mathrm{R} 2$ is 0.701 , we can explain/determine $70 \%$ of its variance. Moreover, the variable with more influence in the DO wine customer satisfaction is the expectation generated by them. From $33.26 \%$ of the satisfaction variance explained by expectations $(\beta=0.437$; correlation $=0.761)$ and its medium predictor effect on satisfaction $\left(f^{2}=0.317\right)$, it can be inferred that these parameters bear out the direct and positive influence of expectations on customer satisfaction and thus confirm hypothesis H4 (customer expectations positively impact on model satisfaction).

Another variable that also influences the perception of customer satisfaction is perceived product quality. Since $21.78 \%$ of satisfaction variance is interpreted by perceived product quality $(\beta=0,619$; correlation $=0.619)$, with a high predictor effect on satisfaction $\left(f^{2}=0.622\right)$, hypothesis H9 (perceived customer product quality positively influences customer satisfaction) is supported. Therefore, customers who can perceive a high level of wine quality after drinking it, will reach high levels of satisfaction and will increase their expectations in future transactions.

Other variables that influence customer satisfaction, such as perceived value and perceived service quality, contribute in a lesser way to achieving customer satisfaction, although obtained results confirm hypothesis H11 (perceived customer-service quality positively influences customer satisfaction), and H12 hypothesis (perceived value directly influences customer satisfaction). Therefore, a customer will be satisfied when the perceived value of the wine intake is higher than its supposed cost. The value can be evaluated as perceived quality/price or benefits/cost ratio.

Finally, the relationship between image and satisfaction was analyzed, with the result that satisfaction variance explained by image is practically null. $(\beta=0.018$; correlation $=$ 0.4 ) and its predictor effect is also null $\left(\mathrm{f}^{2}=0.001\right)$. Consequently, the data do not allow us to appreciate a causal relationship between the variables and hypothesis $\mathrm{H} 2$ (image positively affects wine customer satisfaction). This hypothesis must be discarded. According to perceived value, its variance is moderately explained by its antecedents, achieving a $0.298 \mathrm{R}^{2}$ value, so its antecedents permit it to explain almost $30 \%$ of its variance. 
It is important to highlight the power of expectations as one of the variables that most influences perceived value; $18.95 \%$ of the perceived value variance is explained by expectations $(\beta=0.373$; correlation $=0.508)$ and its predictor effect on the value is medium $\left(f^{2}=0.119\right)$ confirming hypothesis H5 (customer expectations positively influence expected benefits from wine intake compared with its price. Therefore, wine use accomplishes a series of benefits, such as social prestige, feeling calm and enjoying leisure time. It also meets some social needs. Consequently, customers are prepared to pay for a series of wine properties, such as product quality assurance, food security, information and education offered to customers, product image and design. Perceived service quality and perceived product quality intervene moderately on customer perceived value formation. The obtained results are important to evaluate the relationship between product quality and perceived value, although the $4.41 \%$ variance of perceived value is explained by product quality $(\beta=0.106$; correlation $=0.416)$, with a medium predictor effect on perceived value $\left(\mathrm{f}^{2}=0.179\right)$. The correspondent $t$-student value is 1.529 and the $p$-value attained is 0.536 . These data are not significant so hypothesis $\mathrm{H} 8$ (perceived product quality will have a positive effect on the customer's perceived value) must be rejected. Conversely, the values relating to perceived service quality and perceived value by customers with a $6.42 \%$ explained variance $(\beta=0.173$; correlation $=0.371)$ and a low predictor value on perceived value $\left(f^{2}=0.033\right)$ confirm hypothesis H10 (perceived service quality will have a positive effect on customerperceived value). Therefore, customers' perceived value is well linked with perceived service quality, and with weighted benefits against the price paid for the offered characteristics, taking the experience customers acquire after their wine intake as a reference.

Expectations have a direct, positive and causal relationship with perceived product quality and perceived service quality. The variance for perceived product quality explained by expectations is $38.32 \%$, which is one of the highest variances in the model $(\beta=0.619$; correlation $=0.619)$ and also produces a high predictor effect on perceived product quality. Consequently, hypothesis H6 (expectations created by customers increase the perception of product-perceived quality, result perspective) is accepted. It shows that expectations are changing owing to the experience customers acquire after tasting a wine and also because customers are unable to evaluate organoleptic wine qualities objectively. This helps to improve product quality perception based on past relationships, image and the word-of-mouth relationship.

The influence of perceived service quality is less relevant because expectations only explain $16.16 \%$ of the variance of perceived service quality $(\beta=0.402$; correlation $=$ 0.402 ) and has a medium predictor effect on it. According to the data, hypothesis $\mathrm{H} 7$ (expectations created by customers increase the perception of service-perceived quality, functional perception) can be accepted. Perceived service quality is an intangible and formulated concept relating to customer perception that satisfies expectations.

Expectations have only one previous variable, image, which can explain the $18.75 \%$ of the expectation variance $(\beta=0.433$; correlation $=0.433)$ and which generates an average predictor effect on expectations $\left(f^{2}=0.231\right)$. Thus, hypothesis H1 (image positively affects wine customer expectations) is supported.

The image customers form represents wine qualities and benefits for themselves. Customers will trust the image before other factors to obtain expectations of a future intake experience. Likewise, the existence of an indirect effect produced by image on satisfaction must be considered, which is performed indirectly through the mediator variable, expectations. 
According to the loyalty variable, the level where one of its previous variables, satisfaction, explains $39.55 \%$ of its variance $(\beta=0.592$; correlation $=0.668)$ corresponds to the highest percentage of the model with a high predictor effect as well $\left(f^{2}=0,563\right)$. Thus, hypothesis H13 (loyalty is a consequence of customer satisfaction) is sustained. This confirms that there is a positive relationship between satisfaction and repurchase intentions. Satisfaction becomes the main reason for a customer's future intentions, thus acquiring a crucial role in establishing a long-term relationship with customers and, consequently, in achieving company objectives.

Nevertheless, image interferes moderately in customer loyalty formation, since the explained variance by image is $8.11 \%(\beta=0.190$; correlation $=0.427)$ and it also has an average predictor effect on loyalty $\left(f^{2}=0.231\right)$, so hypothesis $\mathrm{H} 3$ (the image customers create through wine intake experiences positively affects wine repurchase), is approved. Without any doubt, a well-positioned corporate image in the market generates more customer confidence and strengthens long-term relationships. Satisfaction and perceived image become customer loyalty drivers.

New ECSI DOP Modeling results:

In reference to the results obtained from the evaluation of the structural model, only two of the originally proposed hypotheses must be rejected, hypothesis 2 and hypothesis 8 . $\mathrm{H} 2$ corresponds to the image and satisfaction relationship and $\mathrm{H} 8$ combines product quality and value variables.

The original modeling is redefined unifying perceived product quality and perceived service quality variables in only one construct to imitate the ASCI model. The principal purpose is to adapt and improve the model for use in the wine sector, thus optimizing its predictive capacity. The non-causal relationship between the image and satisfaction variables remains the same as the original ECSI model, since a causal relationship has been shown in the studied literature; therefore, this relationship has to be evaluated again in the new proposed model.

Therefore, the following hypotheses can be confirmed as the same as in the original model.

H1: Image positively affects wine customer expectations.

$\mathrm{H} 2$ : Image positively affects wine customer satisfaction.

H3: The image customers create through wine intake experiences positively affects wine repurchase.

H4: The confirmation of customers' expectations positively impacts on model satisfaction.

H5: customer expectations positively influence expected benefits from wine intake compared with its price.

H6: Expectations created by customers increase the perception of product-perceived quality.

H7: Perceived quality will have a positive effect on the customer's perceived value.

H8: Perceived customer quality positively influences customer satisfaction.

H9: Perceived value directly influences customer satisfaction.

H10: Loyalty is a consequence of customer satisfaction. 
Figure 4.

ECSI DOP(modified modeling)

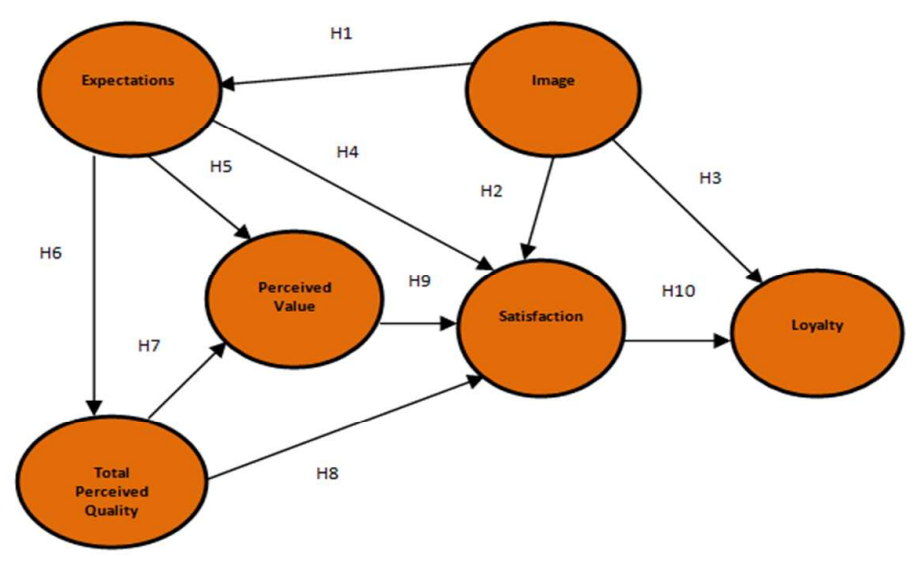

Similarly, as in the previous procedure, firstly, Cronbach's alpha and the composed reliability should be calculated to obtain the reliability of the new model measurement instrument.

According to table VI and in reference to the internal evaluation from the composed reliability and Cronbach's alpha, all the latent variables fulfill the established criterion and so every latent variable is one-dimensional. Moreover, a high reliability of the measurement scales is deduced, with composed reliability values close to 0.9 .

\begin{tabular}{llllr}
\hline Latent Variables & Composed Reliability & Cronbach's Alpha & AVE & \\
\cline { 1 - 3 } Total Quality & 0.865 & 0.818 & 0.517 & \\
Expectations & 0.915 & 0.861 & 0.782 & Table VI. \\
Image & 0.877 & 0.817 & 0.642 & Internal Consistency \\
Loyalty & 0.852 & 0.769 & 0.59 & Evaluation and \\
Satisfaction & 0.885 & 0.826 & 0.658 & Average Variance \\
Value & 0.838 & 0.714 & 0.634 & Extracted, AVE \\
\hline
\end{tabular}

The convergent validity from the Average Variance Extracted (AVE) was calculated. The AVE of each variable should reach more than 0.50 , thus establishing that more than $50 \%$ of the construct variance is interpreted by its indicators, so the model still fulfills the convergence of each variable, as the previous model did.

Discriminant validity was then calculated. It can be observed that the correlation values between the constructs are smaller than the shared average variance among a construct and its measures, so it can be assured that every latent variable fulfills the criterion. Latent variables are, therefore, more correlated with their indicators than with the other latent variables.

\begin{tabular}{lllllllr}
\cline { 1 - 4 } Latent Variables & Total Quality & Expectations & Image & Loyalty & Satisfaction & Value & \\
\cline { 1 - 5 } Total Quality & $\mathbf{0 . 7 1 9}$ & & & & & & Table VII. \\
Expectations & 0.559 & $\mathbf{0 . 8 8 4}$ & & & & & Viscriminant \\
Image & 0.454 & 0.434 & $\mathbf{0 . 8 0 1}$ & & & & Validity Evaluation \\
Loyalty & 0.49 & 0.555 & 0.427 & $\mathbf{0 . 7 6 8}$ & & & Fornell-Larcker \\
Satisfaction & 0.687 & 0.761 & 0.401 & 0.668 & $\mathbf{0 . 8 1 1}$ & & Criterion \\
Value & 0.47 & 0.51 & 0.22 & 0.287 & 0.542 & $\mathbf{0 . 7 9 6}$ & ECSI DOP \\
\hline
\end{tabular}

After asserting the reliability of the new model, the structural model is then resolved. Firstly, $\mathrm{R}^{2}$ shows the variance quantity of the construct, which is explained by the model. 


\begin{tabular}{|c|c|c|c|}
\hline Latent Variables & $\mathbf{R}^{2}$ & Communality & \\
\hline Total Quality & 0.313 & 0.517 & \\
\hline Expectations & 0.189 & 0.782 & \\
\hline $\begin{array}{l}\text { Image } \\
\text { Loyalty }\end{array}$ & 0.476 & $\begin{array}{l}0.642 \\
0.59\end{array}$ & Table VIII. \\
\hline Satisfaction & 0.688 & 0.658 & $\mathrm{R}^{2}$ Endogenous \\
\hline Value & 0.31 & 0.634 & Latent Variables \\
\hline GoF & & & ECSI DOP \\
\hline
\end{tabular}

Likewise, $68.8 \%$ of the satisfaction variance was interpreted by the four previous constructs and almost $47.6 \%$ of the loyalty variable is explained by the satisfaction and image constructs. In contrast, communality values are over 0.5 , which means the model has predictive validity. Later, the size effect $\mathrm{f}^{2}$ of each latent variable was assessed.

\begin{tabular}{|c|c|c|c|c|c|c|c|}
\hline Latent Variables & Total Quality & Expectations & Image & Loyalty & Satisfaction & Value & \\
\hline Total Quality & & & & & 0.227 & 0.072 & \\
\hline Expectations & 0.456 & & & & 0.466 & 0.128 & \\
\hline $\begin{array}{l}\text { Image } \\
\text { Loyalty }\end{array}$ & & 0.232 & & 0.057 & 0 & & $\begin{array}{r}\text { Table IX. } \\
\text { Size Effect } \mathrm{f}^{2}\end{array}$ \\
\hline Satisfaction & & & & 0.561 & & & Latent Variables \\
\hline Value & & & & & 0.032 & & ECSI DOP \\
\hline
\end{tabular}

On evaluating the $\mathrm{f}^{2}$ values previously listed in table IX, it was observed that the relationships with a high predictor effect correspond to the relationships between expectations with total quality, expectations with satisfaction and loyalty with satisfaction. The relationships between total quality and satisfaction, and image and expectations have an average predictor effect. The other relationships have a low predictor effect, except the relationship between image and satisfaction, which resulted null. A predictor increase between the total quality variable with value appeared after the model modification.

\begin{tabular}{|c|c|c|c|c|c|c|c|}
\hline Latent Variable & T-Student & p-value & $\begin{array}{l}\text { Path } \\
\text { Coefficient } \\
(\beta)\end{array}$ & $\begin{array}{l}\text { Variables } \\
\text { Correlation }\end{array}$ & $B * C V$ & $\begin{array}{l}\text { Variance B } \\
\text { explained by A }\end{array}$ & \\
\hline Total Quality -> Satisfaction & 7.521 & 0 & 0.348 & 0.687 & 0.239 & $23.90 \%$ & Table VII. \\
\hline Total Quality-> Value & 3.915 & 0 & 0.27 & 0.47 & 0.127 & $12.70 \%$ & t-student, \\
\hline Expectations -> Total Quality & 10.238 & 0 & 0.559 & 0.559 & 0.313 & $31.30 \%$ & p-value and \\
\hline Expectations -> Satisfaction & 8.72 & 0 & 0.505 & 0.761 & 0.384 & $38.40 \%$ & path \\
\hline Expectations $->$ Value & 4.792 & 0 & 0.359 & 0.51 & 0.183 & $18.30 \%$ & coefficients, \\
\hline Image $->$ Expectations & 7.487 & 0 & 0.434 & 0.434 & 0.188 & $18.80 \%$ & $\%$ variance $b$ \\
\hline Image -> Loyalty & 3.445 & 0.001 & 0.189 & 0.555 & 0.105 & $10.50 \%$ & explained \\
\hline Image $->$ Satisfaction & 0.112 & 0.91 & -0.003 & 0.401 & 0.001 & $0.10 \%$ & by the \\
\hline Satisfaction -> Loyalty & 10.95 & 0 & 0.592 & 0.668 & 0.395 & $39.50 \%$ & latent \\
\hline Value $->$ Satisfaction & 2.27 & 0.023 & 0.122 & 0.542 & 0.066 & $6.60 \%$ & variables \\
\hline
\end{tabular}

Afterwards, the bootstrapping resampling method and the t-student values were evaluated. T-student values over 1.98 show that the relationships with two-tailed test are significant, and if they are over 0.99 , this indicates they are significant with only onetailed test. Besides, if a p-value is smaller than the significant level, established as $\alpha=0.05$, rejecting a null hypothesis when it is true can be avoided.

In reference to table $\mathrm{X}$, all $\mathrm{t}$-student values corresponding to the relationships between the variables are statistically significant, except the relationship between image and 
satisfaction with a 0.112 value, which is under the established 1.98 and shows a p-value over 0.05 . It is important to highlight the increase in the values obtained in the new relationship defined between the total quality variable and value with a $3.915 \mathrm{t}$-student value and a p-value under 0.05 . Therefore, data permit us to appreciate a causal relationship between statistically significant variables.

Each endogenous variable contribution is determined from the path coefficients of the structural model, which comes from the multiplication between the path coefficient and the correlation coefficient among each variable and the endogenous variables. An increase in path coefficients can also be distinguished, highlighting the impact of expectations on total quality with a 0.559 value, expectations on satisfaction with a 0.505 value and the relationship between satisfaction and loyalty with a 0.592 impact. Furthermore, there is an increase in the impact of total quality on satisfaction after unifying quality variables, service and product into only one variable, reaching 0.348 of its weight, and it represents some of the most important data in this new model. Finally, similar to the previous model, the image impact with satisfaction is also null and represents a -0.003 value.

If the Chin (1998) values referred to above are considered, namely that standardized path coefficients should, at least, reach a 0.2 value, and ideally over 0.3 to establish themselves as significant, out of the 10 relationships between the modified model variables, only three are not significant.

In the present study, as in the original model, it is more appropriate to apply the empirical rule proposed by Falk and Miller, whereby a predictor variable should explain at least $1.5 \%$ of the variance in a predicted variable. All the relationships are over the established threshold except for the relationship between image and satisfaction with a $0.1 \%$ value, with the result that it is not significant, as in the original model. With reference to the blindfolding procedure, analyzing the redundancy of crossvalidation $(\mathrm{CV})$ for each latent variable (total quality $(0.137)$, expectations $(0.141)$, loyalty $(0.272)$, satisfaction $(0.439)$, loyalty $(0.272)$, satisfaction $(0.439)$, value $(0.175)$ ), we can conclude that each variable represents a predictive relevance because the $\mathrm{CV}$ value is larger than zero in all the latent variables. Furthermore, the GoF value, calculated in table VIII, is 0.50 . Thus, we can conclude that the model has a good adjustment, with high overall efficiency and the defined variables explain the model perfectly.

New Model Discussion:

According to the values obtained after the new structural model evaluation of the ECSI model in relation to DO Somontano wines, it shows that only hypothesis 2 must be rejected out of the 10 proposed hypotheses. This corresponds to the relationship between image and satisfaction, as occurred in the original model. Likewise, the hypothesis linking total quality with value has already been accepted.

Hypothesis 2, which related the image variable to satisfaction, establishes a 0.401 correlation coefficient that is positive and significant, with a practically null path coefficient $(\beta=-0.003)$ and a $0.112 \mathrm{t}$-student value that is almost zero. Besides, the predictor effect on the variable is also null $\left(\mathrm{f}^{2}=0\right)$ and thus non-significant. Therefore, the satisfaction variance explained by image is also null. That is why the data do not permit us to appreciate a causal relationship between the variables and the hypothesis. Image positively affects wine customer satisfaction must be removed. Conversely, hypothesis 7 (perceived quality will have a positive effect on customerperceived value), which previously had to be rejected (hypothesis 8 , which links product quality with value) has a 0.470 correlation coefficient that is positive and 
significant. The new path coefficient estimates a 0.270 value and the t-student is 3.915 , which is statistically significant. Moreover, the $12.70 \%$ of the value variance is explained by quality and has a low predictor effect on perceived value $\left(f^{2}=0.072\right)$. Therefore, in reference to the results, hypothesis 7 is now accepted, confirming the causal relationship between quality and value.

According to the quality latent variable, in relation to the analysis of the external weights, two of its indicators (information conveyed on quality and product accessibility) are lower than the 0.707 desirable value. Therefore, the formulation of the two aforementioned indicators should be reviewed to estimate that the information obtained from them is relevant to measure and evaluate the quality variable. On the contrary, if more important advances are considered to exist, the actual indicators could be replaced in further research.

Regarding standardized path coefficients, the results are very similar and the behavior in the impact order is almost equal in the two estimations. Although the quality impact on value was too low in the original model estimation, as was the service quality impact on value, it is lower than the established threshold in the validated criterion. Conversely, in the new ECSI model, the quality impact on value improves substantially, thus improving model optimization by combining two quality variables into only one. The $\mathrm{R}^{2}$ indicators show a moderate adjustment in both models and the GoF confirms that the overall efficiency is high; therefore, the defined variables can explain these models properly.

\section{Conclusions}

As a result of the present research, a model developed and adapted by European

Satisfaction Customer Index has been proposed for the wine sector, specifically targeted at DO wines. This model comprises four previous satisfaction variables, namely image, expectations, perceived value, total perceived quality and loyalty, which is a consequent variable of satisfaction. A significant input on customer satisfaction theories and the analysis of DO wine customer behavior are provided by the proposed model.

In this article, model validity has been confirmed, as have the steps followed for its resolution, starting by focusing on the characterization of the variables belonging to this model and its application, which is the purpose of this research.

Pragmatically, the results we have obtained and shown provide a tool that can establish many conclusions for direct use by companies in the sector and that should help them understand their customers' needs and desires better. At the same time, it should facilitate their expectation and perception management and reduce false perceptions or slanted expectations, thus improving a company's chances of achieving customer satisfaction.

With the help of the empirical model analysis, the DO Somontano can learn the importance of customer expectations and perceived quality, which is one of the two most influential factors to achieve satisfaction. Therefore, the DO must give importance to complying with the rules imposed by the Spanish government and ISO standards to generate more value for this collective brand, although it should not underestimate the other variables when the customer satisfaction rate is to be predicted.

The strong relationship between expectations and satisfaction is remarkable and it leads us to assert the predominance of the assimilation phenomenon as opposed to the contrary effect on interpreting satisfaction in the wine sector. The high levels of customer ignorance and insecurity when choosing wine and the subsequent evaluation of it, as well as their emotional character, strengthen the importance of expectations in the modeling of their satisfaction judgment. When this judgment is formed, customers 
are more confident in their expectations or convictions than in their judgments after their wine intake experiences. Consequently, it is difficult for customers to evaluate a product that is becoming increasingly complex and has a high emotional and sensory load.

The analysis also indicates the strong existing relationship between expectations and perceived quality, thus demonstrating that quality perceptions arising from customer expectation determine the perceived result. This demonstration leads us to suggest that the products and services designed by the companies should try to contain mainly features or attributes that customers perceive as rewarding.

In the present situation, corporate image does not significantly influence customer satisfaction. Nevertheless, it does have an important indirect effect on satisfaction through expectations as a mediator variable. Likewise, in the proposed model, considering the satisfaction of all customers has a direct and positive effect on loyalty. However, although satisfaction is a necessary condition, it does not suffice to achieve customer loyalty and image plays an important role in the present case. Therefore, maintaining a good corporate image in the market is required to generate confidence in the customer and also to establish long-term relationships. It is also important to realize that attracting a new customer is more expensive than keeping an existing one, and, therefore, customer loyalty should be bolstered to ensure the company's present and future viability.

If the new proposed model is compared with the original, the obtained data are similar, except for the relationship between perceived total quality and perceived valueaccepting the previously rejected hypothesis - and satisfaction, which improved notably as expected. The relationships between expectations and perceived total quality and satisfaction, including the relationship between satisfaction and loyalty, are more relevant than in the original model. Besides, as mentioned above, the hypothesis that links image with satisfaction was discarded.

An important and interesting new ECSI model contribution for the wine sector with respect to the previous one has been highlighted in this paper. The service and product qualities are linked in a unique variable, total quality, since the preference is for the satisfaction level to be evaluated from a more all-encompassing perspective within the wine sector.

Since the ECSI model has not been implemented previously to study the satisfaction of DO wine consumers, it is a great opportunity for DO Somontano to apply this acquired knowledge to better meet the needs of its potential customers.

According to the data collected in this article, the proposals arising from the measurement of satisfaction are that DO Somontano should invest in sophisticated techniques and in R\&D to increase the quality of its wines and also in appropriate and shocking advertisements, amazing and useful gifts for a loyal customer and premium prizes for expanding its image in customers to upgrade their expectations. Likewise, an improvement in the value of DO Somontano's collective brand would have an important economic impact on the society in this region as it would create more jobs in Somontano's wine industry, which would be promoted as a recognized place for wine tourism, thus establishing more negotiations with the Somontano area, leading to more investments.

In summary, if DO Somontano wishes to stand out from other wine collective brands, it should differentiate itself from its competitors by spending part of its profits on innovation and on improving its brand perception. 


\section{References}

Anderson Eugene W., Fornell, Claes and. Lehmann Donald R., (1994). Customer Satisfaction, Market Share, and Profitability: Findings from Sweden. Journal of Marketing. Vol. 58, No. 3, pp. 53-66.

Anderson, E. W. and Sullivan, M. (1993). The Antecedents and Consequences of Customer Satisfaction for Firms, Marketing Science 12, 125-143.

Anderson, E.W. and Fornell, C. (1994). A customer satisfaction research prospectus. Service Quality: New Dimensions in Theory and Practice. Rust, R.T. and Oliver, R.L. (eds.), Sage CA, pp. 241-268.

Anderson, E.W. and Fornell, C. (2000). Foundations of the American Customer Satisfaction Index, Total Quality Management 11, S869-S882.

Andreassen, T. W. and Lindestad, B. (1998). Customer loyalty and complex services: The impact of corporate image on quality, customer satisfaction and loyalty for customers with varying degrees of service expertise. International Journal of Service Industry Management 9, 7-23.

Askariazad, Mohammad Hossein, Babakhani, Nazila (2015). An application of European Customer Satisfaction Index (ECSI) in business to business (B2B) context. Journal Of Business \& Industrial Marketing 30, 17-31.

Cassel, C. and Eklof, J.A. (2001) Modeling customer satisfaction and loyalty on aggregate levels: experience from the ECSI pilot study. Total Quality Management, 12, 7-8, pp. 834-841.

Cohen, J., Cohen, P., West, S. G., \& Aiken, L. S. (2003). Applied Multiple Regression/Correlation Analysis for the Behavioral Science (3 ed.). New Jersey: Lawrence Erlbaum Associates. Inc.

Chin, W.W. (1998): "The Partial Least Squares Approach to Structural Equation Modeling”, en G.A. Marcoulides [ed.]: Modern Methods for Business Research, pp. 295-336. Mahwah, NJ: Lawrence Erlbaum Associates, Publisher.

Chin, W.W.; (2004): PLS-Graph. Version 3.00. build 1060. University of Houston, Texas, USA.

Chin, W.W.; Newsted, P.R. (1999): Structural Equation Modeling Analysis with Small Samples Using Partial Least Squares, en R. Hoyle [ed.]: Statistical Strategies for Small Samples Research, pp. 307-341. Sage Publications.

Constanza Bianchi; Judy Drennan and Bill Proud. Antecedents of consumer brand loyalty in the Australian wine industry; Journal of Wine Research, volume 25,2014

Constanza Bianchi; Consumer Brand Loyalty in the Chilean wine industry. Journal of Food products marketing. Volume 21, 2015.

Eklöf, J.A. (2000). European Customer Satisfaction Index. Pan-European telecommunication sector report based on the pilot studies 1999. Stockholm: European Organization for Quality and European Foundation for Quality Management.

Enrico Ciavolino \& Jens J. Dahlgaard (2007) ECSI - Customer Satisfaction Modelling and Analysis: A Case Study, Total Quality Management \& Business Excellence $18: 5,545-554$

Ferreira, I. ; Cabral, J. ; Saraiva, P. (2010) An integrated framework based on the ECSI approach to link mould customers' satisfaction and product design. Total Quality Management \& Business Excellence 21:12, 1383-1401.

Fornell, C. (1982): A Second Generation of Multivariate Analysis: An Overview, en C. Fornell [ed.]: A Second Generation of Multivariate Analysis, 1: 1-21. New York: Praeger Publishers. 
Fornell, C.; Bookstein, F.L. (1982): A Comparative Analysis of Two Structural Equation Models: Lisrel and PLS Applied to Market Data, en C. Fornell [ed.]: A Second Generation of Multivariate Analysis, 1: 289-324. New York: Praeger Publishers.

Fornell, C.; Johnson, M. D.; Anderson, E. W.; Cha, J.; and Bryant, B. E. (1996). The American Customer Satisfaction Index: Nature, purpose, and findings. Journal of Marketing, 60 (4), 7-18.

Haenlein M., Kaplan A. (2004). A beginner's Guide to Partial Least Squares Analysis. Understanding Statistics 3, 283-297.

Hair, Jr., J. F., Black, W. C., Babin, B. J., Anderson, R. E., \& Tatham, R. L., 2006. Multivariate Data Analysis (6th ed.). Upper Saddle River, NJ: Pearson Prentice Hall.

Henseler J, Ringle C. M. \& Sinkovics R. R.,(2009). The use of Partial Least Squares Path Modeling in International Marketing. Advances in International Marketing, Vol. 20, 277-319.

Johnson, M. D., Anderson, E. W., \& Fornell, C. (1995). Rational and adaptive performance expectations in a customer satisfaction framework. Journal of Consumer Research, 21(4), 695-707.

Johnson, M. D., Gustafsson, A., Andreassen, T. W., Lervik, L. and Cha, J. (2001). The Evolution and Future of National Customer Satisfaction Index Models, Journal of Economic Psychology 22, 217-245.

Johnson, M.; Anderson, E. W.; Fornell, C. (1995). Rational and adaptive performance expectations in a customer satisfaction framework. Journal of Consumer Research, 21 (March), 695-707.

Kristenensen, K., Martensen, A., and Gronholdt, L: (1999). Measuring the impact of buying behavior on customer satisfaction. Total Quality Management, 10(4-5), 602-614.

Martensen, A., Grønholdt, L. and Kristensen, K. (2000). The Drivers of Customer Satisfaction and Loyalty, Cross-Industry Findings From Denmark, Total Quality Management 11, 8544-8553.

Mojtaba Kaveh, Seyed Alireza Mosavi and Mahnoosh Ghaedi. The application of European customer satisfaction index (ECSI) model in determining the antecedents of satisfaction, trust and repurchase intention in five-star hotels in Shiraz, Iran, African Journal of Business Management Vol. 6(1), pp. 6103-6113, 16 May, 2012.

Oliver, R.L. (1980). A cognitive model of the antecedents and consequences of satisfaction decisions. Journal of Marketing Research, 27, 460-469.

Santiago Ospina Pinzón and Irene Gil Saura (2011), National index of consumer satisfaction. A proposal for a review of literature, Cuad.Adm. vol.24 no.43 Bogotá July/Dec. 2011.

Tenenhaus M. (2008). Component-based Structural Equation Modeling. Total Quality Management \& Business Excellence Vol. 19, No. 7\&8. P. 87-886.

Tenenhaus, M. (2003). Comparison between PLS and LISREL approaches for structural equation modeling: application to the measure of Customer Satisfaction. PLS'03 "Focus on customer" - PLSand related methods, Lisbon, Decisia.

Woodruff, R.B.; Schumann, D.W. and Gardial, S.F. (1993). Understanding value and satisfaction from the customer's point of view. Survey of Business, vol. 28 (Verano/Otoño), pp. 33-40. 
Yuan Jingxue, Alastair Morrison, Liping Cai and Sally Linton; A model of wine tourist behaviour: a festival approach. International Journal of Tourism Research, 25 february 2008 